\title{
Forced periodic operations of a chemical reactor for methanol synthesis - the search for the best scenario based on Nonlinear Frequency Response Method. Part II Simultaneous modulation of two inputs
}

Daliborka Nikolić $^{\mathrm{a}, *}$, Carsten Seidel ${ }^{\mathrm{b}}$, Matthias Felischak ${ }^{\mathrm{c}}$, Tamara Miličić ${ }^{\mathrm{d}}$, Achim Kienle ${ }^{\mathrm{b}, \mathrm{c}}$, Andreas Seidel-Morgenstern ${ }^{\mathrm{b}, \mathrm{c}}$, Menka Petkovska $^{\mathrm{d}}$

${ }^{a}$ University of Belgrade, Institute of Chemistry, Technology and Metallurgy, Njegoševa 12, 11000 Belgrade, Serbia

${ }^{\mathrm{b}}$ Otto-von-Guericke University, Universitätsplatz 2, 39106 Magdeburg, Germany

${ }^{\mathrm{c}}$ Max-Planck Institute for Dynamics of Complex Technical Systems, Sandtorstrasse 1, 39106

Magdeburg, Germany

${ }^{\mathrm{d}}$ University of Belgrade, Faculty of Technology and Metallurgy, Department of Chemical Engineering, Karnegijeva 4, 11000 Belgrade, Serbia

\begin{abstract}
The analysis of the potential to improve performance of a methanol synthesis reactor through forced periodical operations by Nonlinear Frequency Response method is presented. The methanol synthesis in an isothermal and isobaric lab-scale CSTR is considered. First, the analysis was performed for single input modulations (in Part I), which showed that significant improvements can't be achieved. Here, the study is extended to analysis of simultaneous modulations of two inputs. All possible input combinations (6 cases) are analysed and the optimal forcing parameters, maximizing the time-average methanol production, were determined. For all combinations the improvement is possible, but for some cases it is not significant. The highest improvement is predicted for simultaneous modulation of the inlet partial pressure of $\mathrm{CO}$ and the inlet volumetric flow rate. This case, for which it is possible to achieve up to $33.51 \%$ of methanol production, is analysed it detail and optimized using multiobjective optimization.
\end{abstract}

Keywords: Forced periodic operation, Methanol synthesis, Non-linear frequency response, Process improvement, Simultaneous modulation of two inputs, Multi-objective optimization *Corresponding author. Tel.: +381 113640 221, e-mail address: daliborkan@ihtm.bg.ac.rs 


\section{Introduction}

Forced periodic operations, performed by forced periodic modulations of one or more inputs, can be considered as intensified processes, which, by proper choice of the modulated inputs and forcing parameters, could lead to significant process improvements (Van Gerven and Stankiewicz, 2009; Petkovska and Seidel-Morgenstern, 2013). The investigation of forced periodic operations in the field of chemical engineering, especially reactor engineering, became an attractive topic for researchers worldwide. Previous investigations showed that different reactor performances (e.g. conversion, selectivity, productivity...etc.) can be improved by implementation of forced periodic operations (Bailey 1973; Chen et al., 1994; Douglas 1972; Renken 1972; Schadlich et al. 1983; Silveston 1987; Silveston et al., 1995; Silveston 1998; Silveston and Hudgins, 2013; Sterman 1990a, 1990b, 1991).

Nevertheless, in some cases, forced periodic operations could lead to deterioration of timeaverage process performances. Therefore, theoretical prediction and evaluation of possible process improvement, prior to any experimental investigation, is an important task (Petkovska and Seidel-Morgenstern, 2013). In our previous work we introduced the Nonlinear Frequency Response (NFR) method for evaluation of possible improvements owing to periodic operations, as well as for evaluation of optimal forcing parameters and conditions which should be satisfied in order to obtain the highest possible improvement (Currie et al., 2018; Marković et al. 2008; Nikolić-Paunić and Petkovska, 2013; Nikolić et al., 2014a, 2014b, 2015, 2016a, 2016b, 2020; Nikolić, 2016; Nikolić and Petkovska, 2016; Petkovska et al., 2010, 2018 Petkovska and SeidelMorgenstern, 2013; Živković et al. 2020a; 2020b).

In this two-part manuscript, the NFR method is used to perform a systematic search for the periodic process which provides the highest improvements, considering a well-mixed reactor in which heterogeneously catalysed methanol synthesis takes place. In Part I of this work, the NFR analysis was used for evaluating possible improvements in cases of single input modulations, with the main conclusion that this approach was not attractive. In this manuscript (Part II), it is shown that significant improvements are possible for some cases of simultaneous modulations of two inputs.

\section{Nonlinear frequency response method for simultaneous modulation of two inputs}

Frequency response of a nonlinear system is a complex periodic function (Douglas, 1972). In this study, the frequency response of a nonlinear system is analysed using the Nonlinear Frequency Response (NFR) method. This method uses the concept of higher order frequency response functions (FRFs), which is based on Volterra series and the generalized Fourier 
transform (Marković et al, 2006, Petkovska and Seidel-Morgenstern, 2013; Volterra, 1959; Winer and Spina, 1980). The NFR method can be applied to stable weakly nonlinear systems (Petkovska and Seidel-Morgenstern, 2013; Volterra, 1959; Winer and Spina, 1980). In Part I of this paper, the implementation of the NFR method for periodic operations with single input modulations was explained, and here we give the basic facts of its implementation for the cases of simultaneous modulations of two inputs. More details can be found in our previous publications (e.g. Nikolić and Petkovska, 2013; Petkovska et al., 2018).

If one or more inputs of a weakly nonlinear systems is/are periodically modulated around a previously established steady-state, the frequency response of the system output is obtained as a sum of the output steady-state value $\left(y_{s}\right)$, the basis harmonic $\left(y_{I}\right)$, an infinite number of higher harmonics $\left(y_{I I}, y_{I I I}, \ldots\right)$ and a non-periodic (DC) term ( $\left.y_{D C}\right)$ (Marković et al, 2006, Petkovska and Seidel-Morgenstern, 2013; Petkovska et al., 2018):

$y(t)=y_{s}+y_{D C}+y_{I}+y_{I I}+y_{I I I}+\cdots$

In order to evaluate the potential of a forced periodical operation of a system, it is only necessary to predict the DC component of the output of interest, as it determines the time-average performance of the analysed system.

The DC component of an output $y$, for the case when two inputs (e.g. $x$ and $z$ ) are periodically modulated, can be given as a sum of the contributions of the DC component related to the single inputs $(x$ and $z$ ) separately and the contribution of the DC component originating from the crosseffect of both inputs (Nikolić and Petkovska, 2013):

$y_{D C}=y_{D C, x}+y_{D C, z}+y_{D C, x z}$

For co-sinusoidal modulations of inputs $x$ and $z$, with equal frequencies $\omega$, input amplitudes $A_{x}$ and $A_{z}$, respectively and phase difference $\varphi$ between them, the separate contributions of the two inputs to the DC component can be approximately evaluated from the corresponding ASO FRFs, in the same way as explained in Part I:

$y_{D C, \text { in }} \approx 2\left(\frac{A_{\text {in }}}{2}\right)^{2} G_{y, \text { in in }}^{(2)}(\omega,-\omega) \quad$ in $=x$ or $z$

while the contribution of the cross-effect can be approximately evaluated in the following way (Nikolić and Petkovska, 2013; Petkovska et al., 2018):

$y_{D C, x z} \approx 2\left(\frac{A_{x}}{2}\right)\left(\frac{A_{z}}{2}\right) G_{y, x, z}^{*(2)}(\omega, \varphi)$

$G_{y, x, z}^{*(2)}(\omega, \varphi)$ is the so-called cross ASO term, which correlates the output $y$ with both modulated inputs $(x$ and $z$ ). It is a function of both frequency and phase difference between the two 
modulated inputs, and is evaluated based on the cross asymmetrical second order FRF $\left(G_{y, x, z}^{(2)}(\omega,-\omega)\right)$, in the following way:

$\left.\left.G_{y, x, z}^{*(2)}(\omega, \varphi)=\cos (\varphi) \operatorname{Re}\left(G_{y, x, z}^{(2)}(\omega,-\omega)\right)\right)+\sin (\varphi) \operatorname{Im}\left(G_{y, x, z}^{(2)}(\omega,-\omega)\right)\right)$

Thus, for the case of modulation of two inputs ( $x$ and $z$ ), in order to evaluate the possible improvement of the output $y$, it is necessary to derive three ASO FRFs: two of them correlating the output to each of the inputs $\left(G_{y, x, x}^{(2)}(\omega,-\omega)\right.$ for input $x$ and, $G_{y, z, z}^{(2)}(\omega,-\omega)$ for input $\left.z\right)$ and one cross ASO function $\left(G_{y, x, z}^{(2)}(\omega,-\omega)\right.$, correlating the output to both modulated inputs) (Nikolić Paunić and Petkovska, 2013, Petkovska et al., 2018). The overall DC component of the output $y$, written as follows:

$y_{D C} \approx 2\left(\frac{A_{x}}{2}\right)^{2} G_{y, x, x}^{(2)}(\omega,-\omega)+2\left(\frac{A_{z}}{2}\right)^{2} G_{y, z, z}^{(2)}(\omega,-\omega)+2\left(\frac{A_{x}}{2}\right)\left(\frac{A_{z}}{2}\right) G_{y, x, z}^{*(2)}(\omega, \varphi)$

should be calculated for a chosen set of forcing parameters (forcing frequency, forcing amplitudes and phase difference) (Nikolić and Petkovska, 2013; Nikolić et al., 2015; Nikolić et al., 2016a; 2016b). In principle, it is possible find a set of forcing parameters resulting the periodic operation with highest improvement (Nikolić and Petkovska, 2013, Nikolić, 2016, Petkovska el al, 2016).

The phase difference is a crucial parameter for a periodic operation with simultaneous modulations of two inputs, considering that its appropriate choice guaranties that the cross term of the DC component has the desirable sign. Furthermore, by choosing the optimal phase difference, the cross-effect can be maximized (Felischak 2020; Felischak et al. 2021; Nikolić, 2016; Nikolić and Petkovska, 2013; Petkovska et al., 2018). The optimal phase difference, maximizing the DC component can be determined based only on the cross ASO FRF, in the following way (Nikolić and Petkovska, 2013):

$\varphi_{\text {opt }}=\arctan \left(\frac{\operatorname{Im}\left(G_{y, x, z}^{(2)}(\omega,-\omega)\right)}{\operatorname{Re}\left(G_{y, x, z}^{(2)}(\omega,-\omega)\right)}\right)$

The derivation procedure of the FRFs is standard and it can be found in our previous publications (Marković et al., 2008; Petkovska and Seidel-Morgenstern, 2013; Nikolić Paunić and Petkovska, 2013; Nikolić et al., 2014a; 2014b; 2015; 2016a; 2016b; Nikolić and Petkovska, 2016; Petkovska et al., 2010; 2018, Petkovska and Seidel-Morgenstern 2013). The derivation procedure is recurrent, so the first order FRFs should be derived first and then the asymmetrical second order FRFs. 


\section{$3 \quad$ Methanol synthesis reaction}

The performance of a forced periodically operated chemical reactor in which methanol is produced from synthesis gas (mixture of $\mathrm{CO}, \mathrm{CO}_{2}$ and $\mathrm{H}_{2}$ ), through hydrogenation of $\mathrm{CO}$ and $\mathrm{CO}_{2}$, using a commercial $\mathrm{Cu} / \mathrm{ZnO} / \mathrm{Al}_{2} \mathrm{O}_{3}$ catalyst, is analysed. The hydrogenation reactions are (Graaf et al. (1988)):

$$
\begin{aligned}
& \mathrm{CO}+2 \mathrm{H}_{2} \rightleftarrows \mathrm{CH}_{3} \mathrm{OH} \\
& \mathrm{CO}_{2}+3 \mathrm{H}_{2} \rightleftarrows \mathrm{CH}_{3} \mathrm{OH}+\mathrm{H}_{2} \mathrm{O}
\end{aligned}
$$

In addition, the reverse water-gas shift reaction (RWGS) is taking place according to:

$$
\mathrm{CO}_{2}+\mathrm{H}_{2} \rightleftarrows \mathrm{CO}+\mathrm{H}_{2} \mathrm{O}
$$

The analysis of forced periodic operation of methanol synthesis is based on the kinetic model presented in (Seidel et al., 2018; 2020). The kinetic model and parameters used in this study were given in Part I of this work.

\section{Application of the NFR method for evaluating the possible performance improvements of methanol synthesis reactor with simultaneous periodic modulations of two inputs}

In this Section, the NFR method is applied for analysis and evaluation of possible improvements of methanol production for forced period operations with simultaneous modulation of two inputs. The analysis is performed for a laboratory-scale uniformly mixed Micro-Berty reactor, which was used for kinetic measurements (Vollbrecht, 2007). It is planned that the results of the theoretical analysis, presented below, will be experimentally validated using this same reactor type.

\subsection{Mathematical model}

The starting point for application of the NFR method is the mathematical model of the analysed system, which has been given in Part I of this paper. We repeat here just the main facts regarding the model. The mathematical model is based on the following assumptions: the reaction of methanol synthesis occurs in an isothermal and isobaric CSTR, the gas phase is ideal in the range of operation parameters, the adsorption equilibrium between the solid and the fluid phase exists, the adsorption processes follow the Langmuir-Hinshelwood mechanism, the catalyst deactivation can be neglected and only the reactions defined in equations (8-10) take place.

The mathematical model of the analysed system can be described with eight ordinary differential equations: the material balances for each of the six components present in the system $\left(\mathrm{CH}_{3} \mathrm{OH}\right.$, 
$\mathrm{CO}_{2}, \mathrm{CO}, \mathrm{H}_{2}, \mathrm{H}_{2} \mathrm{O}$ and $\mathrm{N}_{2}$ (inert)), the total material balance (from which the volumetric flow rate of the outlet stream is evaluated) and an equation which describes the catalyst dynamics.

Considering that for the NFR analysis it is convenient to use a dimensionless mathematical model, the dimensionless variables are defined as relative deviations from the corresponding steady-state values (Appendix A) and incorporated into the starting model equations. Afterwards, all nonlinear terms in the mathematical model are expanded into Taylor series form around the steady-state point, as already presented in Part I of this paper.

\subsection{Inputs, outputs and frequency response functions (FRFs)}

For the analysed system, it is possible to modulate periodically four different inputs: the partial pressures of all reactants in the feed stream $\left(\mathrm{CO}_{2}, \mathrm{CO}, \mathrm{H}_{2}\right)$ and the volumetric flow-rate of inlet steam. The outputs are: the partial pressures of all components in the outlet stream (of the reactants and products, i.e. $\mathrm{CH}_{3} \mathrm{OH}, \mathrm{CO}_{2}, \mathrm{CO}, \mathrm{H}_{2}, \mathrm{H}_{2} \mathrm{O}$ ), the fraction of reduced active centres on the catalyst surface and the volumetric flow-rate of the outlet stream.

The vectors of all inputs which can be modulated (designated as $\mathbf{X}$ and $\mathbf{Z}$ ) and the vector of output variables (designated as $\mathbf{Y}$ ), are given in the dimensionless form, as follows:

$$
\mathbf{X}=\mathbf{Z}=\left[\begin{array}{c}
P_{\mathrm{CO}_{2}, 0} \\
P_{\mathrm{CO}, 0} \\
P_{\mathrm{H}_{2}, 0} \\
v_{0}
\end{array}\right] \quad \mathbf{Y}=\left[\begin{array}{c}
P_{\mathrm{CH}_{3} \mathrm{OH}} \\
P_{\mathrm{CO}_{2}} \\
P_{\mathrm{CO}} \\
P_{\mathrm{H}_{2}} \\
P_{\mathrm{H}_{2} \mathrm{O}} \\
\Phi \\
v
\end{array}\right]
$$

The analysis for single input modulations, given in Part I of this paper, showed that no significant improvement could be achieved. Therefore, here we give the analysis for simultaneous modulation of all possible combinations of two inputs. Six cases are analysed in total, three combinations when inputs are partial pressures of two reactants:

- partial pressures of $\mathrm{CO}_{2} \& \mathrm{CO}$ in the feed stream

- partial pressures of $\mathrm{CO}_{2} \& \mathrm{H}_{2}$ in the feed stream

- partial pressures of $\mathrm{CO} \& \mathrm{H}_{2}$ in the feed stream

and three combinations of the partial pressure of one reactant and the inlet volumetric flow-rate:

- partial pressure of $\mathrm{CO}_{2}$ in the feed stream and the inlet volumetric flow-rate

- partial pressure of CO in the feed stream and the inlet volumetric flow-rate and

- partial pressure of $\mathrm{H}_{2}$ in the feed stream and inlet the volumetric flow-rate.

For each of the six cases, the partial pressure of inert $\left(\mathrm{N}_{2}\right)$ is also periodically modulated in a way to maintain a constant total pressure (see Appendices B and C). The inert does not participate in 
the chemical reactions nor in the adsorption on the catalyst surface and its modulation does not influence the reactor outputs. It only influences the value of outlet pressure of inert $\left(\mathrm{N}_{2}\right)$ which is not subject of our analysis.

The FRFs, which correlate each output $Y_{y}(y=1, \ldots, 7)$ with each modulated input $X_{x}(x=1, \ldots, 4)$, for single input modulations: the first order frequency response functions (FRFs), $G_{y, x}^{(1)}(\omega)$ and the asymmetrical second order frequency response functions, $G_{y, x, x}^{(2)}(\omega,-\omega)$ were derived and analysed in Part I of this paper. In this, Part II, the cross ASO FRFs $G_{y, x, z}^{(2)}(\omega,-\omega)$, which correlate the output $Y_{y}$ to modulated inputs $X_{x}$ and $Z_{z}$ (for all six defined combinations) are derived.

The cross asymmetrical second order FRFs are derived by applying the standard derivation procedure (Nikolić and Petkovska, 2013; Nikolić, 2016; Petkovska et al., 2018).

\subsection{Derivation of the cross FRFs}

In order to derive the cross ASO FRFs for synchronous simultaneous modulations of inputs $X_{x}$ and $Z_{z}$, it is most convenient to define them in the following way:

$$
\begin{aligned}
& X_{x}(\tau)=A_{x} \cos (\omega \tau)=\left(\frac{A_{x}}{2}\right) e^{j \omega \tau}+\left(\frac{A_{x}}{2}\right) e^{-j \omega \tau} \\
& Z_{z}(\tau)=A_{z} \cos (\omega \tau+\varphi)=\left(\frac{A_{z}}{2} e^{j \varphi}\right) e^{j \omega \tau}+\left(\frac{A_{z}}{2} e^{-j \varphi}\right) e^{-j \omega \tau}
\end{aligned}
$$

In that case, the output $Y_{y}$, can be expressed in the form of Volterra series (Volterra, 1959):

$$
\begin{aligned}
Y_{y}=\left(\frac{A_{x}}{2}\right) e^{j \omega \tau} G_{y, x}^{(1)}(\omega)+\left(\frac{A_{x}}{2}\right) e^{-j \omega \tau} G_{y, x}^{(1)}(-\omega)+\cdots+2\left(\frac{A_{x}}{2}\right)^{2} e^{0} G_{y, x, x}^{(2)}(\omega,-\omega)+\cdots \\
+\left(\frac{A_{z}}{2}\right) e^{j \omega \tau} e^{j \varphi} G_{y, z}^{(1)}(\omega)+\left(\frac{A_{z}}{2}\right) e^{-j \omega \tau} e^{-j \varphi} G_{y, z}^{(1)}(-\omega)+\cdots+2\left(\frac{A_{z}}{2}\right)^{2} e^{0} G_{y, z, z}^{(2)}(\omega,-\omega) \\
+\cdots+\left(\frac{A_{x}}{2}\right)\left(\frac{A_{z}}{2}\right)\left(e^{-j \varphi} G_{y, x, z}^{(2)}(\omega,-\omega)+e^{j \varphi} G_{y, x, z}^{(2)}(-\omega, \omega)\right)+\cdots
\end{aligned}
$$

Following the standard derivation procedure the expressions for the dimensionless inputs (Eqs. (12 and 13)) and outputs (Eq.(14)), are incorporated in the dimensionless mathematical model equations (given in Part I of this paper). The cross ASO FRFs are obtained by collecting the nonperiodic terms with $\left(\left(\frac{A_{x}}{2}\right)\left(\frac{A_{z}}{2}\right) e^{-j \varphi}\right)$ and equating them with zero.

It is most convenient to present the resulting sets of algebraic equations in the matrix form: 


$$
\left[\begin{array}{ccc}
\gamma_{11} & \cdots & \gamma_{17} \\
\vdots & \ddots & \vdots \\
\gamma_{71} & \cdots & \gamma_{77}
\end{array}\right] \times\left[\begin{array}{l}
G_{1, x, z}^{(2)}(\omega,-\omega) \\
G_{2, x, z}^{(2)}(\omega,-\omega) \\
G_{3, x, z}^{(2)}(\omega,-\omega) \\
G_{4, x, z}^{(2)}(\omega,-\omega) \\
G_{5, x, z}^{(2)}(\omega,-\omega) \\
G_{6, x, z}^{(2)}(\omega,-\omega) \\
G_{7, x, z}^{(2)}(\omega,-\omega)
\end{array}\right]=\left[\begin{array}{c}
\Lambda_{1, x, z} \\
\Lambda_{2, x, z} \\
\Lambda_{3, x, z} \\
\Lambda_{4, x, z} \\
\Lambda_{5, x, z} \\
\Lambda_{6, x, z} \\
\Lambda_{7, x, z}
\end{array}\right], x=1,2 \text { or } 3, z=x+1, x+2 \text { or } x+3, z \leq 4
$$

The cross ASO FRFs are obtained as the solution of matrix equation (15):

$$
\left[\begin{array}{c}
G_{1, x, z}^{(2)}(\omega,-\omega) \\
G_{2, x, z}^{(2)}(\omega,-\omega) \\
G_{3, x, z}^{(2)}(\omega,-\omega) \\
G_{4, x, z}^{(2)}(\omega,-\omega) \\
G_{5, x, z}^{(2)}(\omega,-\omega) \\
G_{6, x, z}^{(2)}(\omega,-\omega) \\
G_{7, x, z}^{(2)}(\omega,-\omega)
\end{array}\right]=\left[\begin{array}{ccc}
\gamma_{11} & \cdots & \gamma_{17} \\
\vdots & \ddots & \vdots \\
\gamma_{71} & \cdots & \gamma_{77}
\end{array}\right]^{-1} \times\left[\begin{array}{c}
\Lambda_{1, x, z} \\
\Lambda_{2, x, z} \\
\Lambda_{3, x, z} \\
\Lambda_{4, x, z} \\
\Lambda_{5, x, z} \\
\Lambda_{6, x, z} \\
\Lambda_{7, x, z}
\end{array}\right], x=1,2 \text { or } 3, z=x+1, x+2 \text { or } x+3, z \leq 4
$$

The definitions of auxiliary functions $\Lambda_{y, x, z}(y=1, \ldots, 7, x=1,2,3, z=2,3,4)$ are given in Appendix D. The auxiliary coefficients $\gamma_{i, j}(i, j=1, \ldots, 7)$ were defined in Part I of this paper. 


\subsection{Evaluation of possible improvement}

As explained in Part I of this paper, the forced periodic operations are implemented in order to achieve the improvement of different reactor performances, e.g. increase of methanol production, conversion or yield. The increase of all these performances can be evaluated based on timeaverage outlet molar flow-rate of methanol.

The methanol molar flow-rate can be evaluated from the methanol partial pressure and volumetric flow-rate of the outlet stream:

$\dot{n}_{\mathrm{CH}_{3} \mathrm{OH}}=\frac{p_{\mathrm{CH}_{3} \mathrm{OH}} \dot{V}}{R T}$

or in the dimensionless form:

$\dot{N}_{\mathrm{CH} 3 \mathrm{OH}}=\frac{\dot{n}_{\mathrm{CH} 3 \mathrm{OH}}-\dot{n}_{\mathrm{CH} 3 \mathrm{OH}, \mathrm{S}}}{\dot{n}_{\mathrm{CH} 3 \mathrm{OH}, \mathrm{S}}}=\frac{p_{\mathrm{CH} 3 \mathrm{OH}} \dot{V}-p_{\mathrm{CH} 3 \mathrm{OH}, \mathrm{s}} \dot{V}_{\mathrm{S}}}{p_{\mathrm{CH} 3 \mathrm{OH}, \mathrm{S}} \dot{S}_{\mathrm{S}}}=P_{\mathrm{CH} 3 \mathrm{OH}}+v+P_{\mathrm{CH} 3 \mathrm{OH}} v$

Using the NFR method, the mean (time-average) value of the outlet molar flow rate of methanol, $\left(\dot{n}_{\mathrm{CH}_{3} \mathrm{OH}}\right)_{\text {mean }}$, for simultaneous co-sinusoidal modulations of inputs $x$ and $z$ can be approximately calculated using the following expression:

$\left(n_{\mathrm{CH} 3 \mathrm{OH}}\right)_{\text {mean }} \approx$

$\dot{n}_{C H 3 O H, S}\left(1+2\left(\frac{A_{x}}{2}\right)^{2} H_{1, x, x}^{(2)}(\omega,-\omega)+2\left(\frac{A_{z}}{2}\right)^{2} H_{1, Z, Z}^{(2)}(\omega,-\omega)+2\left(\frac{A_{x}}{2}\right)\left(\frac{A_{z}}{2}\right) H_{1, x, Z}^{*(2)}(\omega, \varphi)\right)$

where $H_{1, x, x}^{(2)}(\omega,-\omega)$ and $H_{1, z, z}^{(2)}(\omega,-\omega)$ are the ASO FRFs frequency response functions which correlate the dimensionless outlet molar flow-rate of methanol, separately, to modulated inputs $x$ and $z$, respectively (both derived and given in Part I of this paper), while $H_{1, x, z}^{*(2)}(\omega, \varphi)$ is the cross ASO term which correlates the outlet molar flow-rate of methanol to both modulated inputs $x$ and $z$.

$\dot{n}_{\mathrm{CH}_{3} \mathrm{OH}, \mathrm{S}}=\frac{\left(p_{\mathrm{CH}_{3} \mathrm{OH}} \dot{\mathrm{V}}\right)_{s}}{R T}$

is the steady-state value of the outlet molar flow-rate.

This cross ASO term, which is a function of the forcing frequency $\omega$ and the phase shift between the two inputs $\varphi$, is obtained from the corresponding cross ASO FRF and the phase difference in an analogous way as in eq. (5):

$H_{1, x, z}^{*(2)}(\omega, \varphi)=\cos (\varphi) \operatorname{Re}\left(H_{1, x, z}^{(2)}(\omega,-\omega)\right)+\sin (\varphi) \operatorname{Im}\left(H_{1, x, z}^{(2)}(\omega,-\omega)\right)$ 
In Part I of this work we derived the relation between the ASO FRF corresponding to the outlet molar flow rate and input $x\left(H_{1, x, x}^{(2)}(\omega,-\omega)\right)$ and the FRFs corresponding to the outlet methanol partial pressure and the outlet volumetric flow rate:

$$
\begin{aligned}
& H_{1, x, x}^{(2)}(\omega,-\omega)=G_{1, x, x}^{(2)}(\omega,-\omega)+G_{7, x, x}^{(2)}(\omega,-\omega)+\frac{1}{2}\left(G_{1, x}^{(1)}(\omega) G_{7, x}^{(1)}(-\omega)+G_{1, x}^{(1)}(-\omega) G_{7, x}^{(1)}(\omega)\right), \\
& x=1,2,3 \text { or } 4
\end{aligned}
$$

In an analogous way, here we derive the relation for the cross ASO FRF $H_{1, x, z}^{(2)}(\omega,-\omega)$ :

$H_{1, x, z}^{(2)}(\omega,-\omega)=G_{1, x, z}^{(2)}(\omega,-\omega)+G_{7, x, z}^{(2)}(\omega,-\omega)+G_{1, x}^{(1)}(\omega) G_{7, z}^{(1)}(-\omega)+G_{1, z}^{(1)}(-\omega) G_{7, x}^{(1)}(\omega)$

$x=1,2$ or $3, z=x+1, x+2$ or $x+3, z \leq 4$

Based on the mean value of the methanol outlet molar flow rate, several performance indicators were defined (same as the one used in Part I of this paper):

- normalized methanol production per unit mass of catalyst:

$\left(\dot{n}_{\mathrm{CH}}^{\text {norm } \mathrm{OH}}\right)_{P O}=\frac{\left(\dot{n}_{\mathrm{CH}_{3} \mathrm{OH}}\right)_{\text {mean }}}{m_{\text {cat }}}$

- yield of methanol based of total carbon and

$$
\left(Y_{\mathrm{CH}_{3} \mathrm{OH}}^{\mathrm{totC}}\right)_{\mathrm{PO}}=\frac{\left(\dot{n}_{\mathrm{CH} 3 \mathrm{OH}}\right)_{\text {mean }}}{\left(\dot{n}_{\mathrm{CO} 2}+\dot{n}_{\mathrm{CO}}\right)_{0, \text { mean }}}
$$

- yield of methanol based on hydrogen:

$$
\left(Y_{\mathrm{CH}_{3} \mathrm{OH}}^{\mathrm{H}_{2}}\right)_{P O}=2 \frac{\left(\dot{n}_{\mathrm{CH} 3 \mathrm{OH}}\right)_{\text {mean }}}{\left(\dot{n}_{\mathrm{H} 2,0}\right)_{\text {mean }}}
$$

For simultaneous modulation of partial pressures of two reactants $\left(\mathrm{CO}_{2} \& \mathrm{CO}, \mathrm{CO}_{2} \& \mathrm{H}_{2}\right.$, $\mathrm{CO \&} \mathrm{H}_{2}$ ), the mean values of the molar flow-rates of the reactants in the feed stream are identical to their steady-state values. On the other hand, for simultaneous modulation of partial pressure of one reactant and inlet volumetric flow rate, the mean value of the inlet molar flow-rate of the modulated reactant is different from the corresponding steady-state value, and can be can be calculated using on the following common equation:

$$
\left(\dot{n}_{i}\right)_{0, \text { mean }}=\left(\dot{n}_{i}\right)_{0, s}\left(1+\frac{A_{i} A_{f}}{2} \cos (\varphi)\right), i=\mathrm{CO}_{2}, \mathrm{CO} \text { or } \mathrm{H}_{2}
$$

The definitions of the yields for these cases are given in Table 1. 
Table 1 The definitions of the yield of methanol based on total carbon and based on hydrogen for simultaneous modulation of the partial pressure of one reactant and the inlet volumetric flow-rate

\begin{tabular}{|c|c|c|}
\hline $\begin{array}{l}\text { Modulated inputs } x \\
\text { and } z\end{array}$ & $\begin{array}{l}\text { Yield of methanol } \\
\text { based on total carbon }\end{array}$ & $\begin{array}{l}\text { Yield of methanol } \\
\text { based on hydrogen }\end{array}$ \\
\hline $\begin{array}{l}\text { Inlet partial pressure } \\
\text { of } \mathrm{CO}_{2}(x) \text { and total } \\
\text { inlet volumetric } \\
\text { flow-rate }(z)\end{array}$ & $\begin{array}{l}\left(Y_{\mathrm{CH}_{3} \mathrm{OH}}^{\mathrm{totC}}\right)_{P O} \\
=\frac{\left(\dot{n}_{\mathrm{CH} 3 \mathrm{OH}}\right)_{\text {mean }}}{\left(\dot{n}_{\mathrm{CO} 2}\right)_{0, \text { mean }}+\left(\dot{n}_{\mathrm{CO}}\right)_{0, \mathrm{~S}}}\end{array}$ & \multirow{2}{*}{$\left(Y_{\mathrm{CH}_{3} \mathrm{OH}}^{\mathrm{H}_{2}}\right)_{P O}=2 \frac{\left(\dot{n}_{\mathrm{CH} 3 \mathrm{OH}}\right)_{\text {mean }}}{\left(\dot{n}_{\mathrm{H} 2}\right)_{0, \mathrm{~S}}}$} \\
\hline $\begin{array}{l}\text { Inlet partial pressure } \\
\text { of } \mathrm{CO}(x) \text { and total } \\
\text { inlet volumetric } \\
\text { flow-rate }(z)\end{array}$ & $\begin{array}{l}\left(Y_{\mathrm{CH}_{3} \mathrm{OH}}^{\mathrm{totC}}\right)_{P O} \\
=\frac{\left(\dot{n}_{C H 3 O H}\right)_{\text {mean }}}{\left(\dot{n}_{\mathrm{CO} 2}\right)_{0, \mathrm{~S}}+\left(\dot{n}_{\mathrm{CO}}\right)_{0, \text { mean }}}\end{array}$ & \\
\hline $\begin{array}{l}\text { Inlet partial pressure } \\
\text { of } \mathrm{H}_{2}(x) \text { and total } \\
\text { inlet volumetric } \\
\text { flow-rate }(z)\end{array}$ & $\left(Y_{\mathrm{CH}_{3} \mathrm{OH}}^{\mathrm{totC}}\right)_{P O}=\frac{\left(\dot{n}_{\mathrm{CH} 3 \mathrm{OH}}\right)_{\text {mean }}}{\left(\dot{n}_{\mathrm{CO} 2}+\dot{n}_{\mathrm{CO}}\right)_{0, \mathrm{~s}}}$ & $\left(Y_{\mathrm{CH}_{3} \mathrm{OH}}^{\mathrm{H}_{2}}\right)_{P O}=2 \frac{\left(\dot{n}_{\mathrm{CH} 3 \mathrm{OH}}\right)_{\text {mean }}}{\left(\dot{n}_{\mathrm{H} 2}\right)_{0, \text { mean }}}$ \\
\hline
\end{tabular}

\section{Results and discussion}

\subsection{Periodic operations around the chosen steady-state point}

In this subsection, periodic operations around a chosen steady-state point are analysed, for all six combinations of input modulations. The performance indicator used for evaluation will be the normalized production, defined as the outlet molar flow-rate of methanol per mass of catalyst (Eq. (24)).

The analysis is performed for the same isothermal, isobaric, lab-scale Micro-Berty reactor, (gas volume $10.3 \mathrm{ml}$, mass of catalyst $0.00395 \mathrm{~kg}$ and total pressure $60 \mathrm{bar}$ ) considered in Part I. Also, the same optimal steady-state point used for analysis in Part I is used (temperature $473 \mathrm{~K}$, feed volumetric flow-rate $0.93 \mathrm{ml} / \mathrm{min}$, feed composition: $2.1 \% \mathrm{CO}_{2}, 18.5 \%, 64.4 \% \mathrm{H}_{2}$ and 15 $\% \mathrm{~N}_{2}$ ). For the selected optimal steady-state, the normalized outlet molar flow-rate of methanol is $336.91 \mathrm{mmol} /\left(\operatorname{min~} \mathrm{kg}_{\text {cat }}\right)$, the yield of methanol based on total carbon $61.05 \%$ and the yield of methanol based on hydrogen $39.09 \%$.

As shown in Part I, periodic operations with single input modulations, for all 4 inputs, dominantly lead to reduction of methanol production. As a consequence, in order to maximize the mean normalized outlet molar flow-rate of methanol, it is necessary to optimize, not only the 
phase difference between modulated inputs and the forcing frequency, but also the forcing amplitudes of the modulated inputs. The optimal phase difference maximizing the methanol outlet molar flow-rate can be calculated analytically, based on the corresponding cross ASO $\operatorname{FRF}_{1, x, z}^{(2)}(\omega,-\omega)$ :

$\varphi_{\text {opt }}=\arctan \left(\frac{\operatorname{Im}\left(H_{1, x, z}^{(2)}(\omega,-\omega)\right)}{\operatorname{Re}\left(H_{1, x, z}^{(2)}(\omega,-\omega)\right)}\right)$

Afterwards, the optimal forcing amplitudes are determined numerically, by using a standard Matlab solver (fminmax), in order to maximize the mean outlet molar flow rate of methanol (Eq. 19). The amplitude of the volumetric flow-rate can have values up to 1 (100\%), while the amplitudes of the partial pressures are limited with the maximal possible amplitude of the inert partial pressure that needs to be adjusted in order to keep constant total pressure (see Appendices $\mathrm{B}$ and C). In principle, the optimal amplitudes and phase difference are frequency dependent.

The results of the NFR analysis for each case of simultaneous modulation of two inputs around the optimal steady state are summarized in Table 2 . This table shows the best possible results which can be obtained by each of the 6 possible combinations of inputs. The maximal increase of the normalized methanol production, the corresponding changes of yield of methanol based on total carbon and based on hydrogen, as well as corresponding optimal forcing parameters (amplitudes of both modulated inputs, the dimensionless frequency and the phase difference between the modulated inputs) for which these results are obtained, are presented. 
Table 2. The best results which can be obtained by simultaneous modulations of two inputs

\begin{tabular}{|c|c|c|c|c|c|c|c|}
\hline \multirow{2}{*}{ Modulated inputs $x$ and $z$} & \multirow{2}{*}{$\begin{array}{c}\text { Maximal } \\
\text { increase of } \\
\dot{n}_{\mathrm{CH}_{3} \mathrm{OH}}^{\text {norm }}\end{array}$} & \multirow{2}{*}{$\begin{array}{l}\text { Change of } \\
Y_{\mathrm{CH}_{3} \mathrm{toH}}^{\text {totC }}\end{array}$} & \multirow{2}{*}{$\begin{array}{l}\text { Change of } \\
Y_{\mathrm{CH}_{3} \mathrm{OH}}^{\mathrm{H}_{2}}\end{array}$} & \multicolumn{4}{|c|}{ Optimal forcing parameters } \\
\hline & & & & $A_{x}(-)$ & $A_{z}(-)$ & $\omega(-)$ & $\varphi(\mathrm{rad})$ \\
\hline $\begin{array}{l}\text { Inlet partial pressures of } \\
\mathrm{CO}_{2}(x) \text { and } \mathrm{CO}(z)\end{array}$ & $0.15 \%$ & $+0.15 \%$ & $+0.15 \%$ & 1 & 0.59 & 1.47 & -0.83 \\
\hline $\begin{array}{l}\text { Inlet partial pressures of } \\
\mathrm{CO}_{2}(x) \text { and } \mathrm{H}_{2}(z)\end{array}$ & $0.22 \%$ & $+0.22 \%$ & $+0.22 \%$ & 0.36 & 0.22 & 1.27 & -0.49 \\
\hline $\begin{array}{l}\text { Inlet partial pressures of } \\
\mathrm{CO}(x) \text { and } \mathrm{H}_{2}(z)\end{array}$ & $0.45 \%$ & $+0.45 \%$ & $+0.45 \%$ & 0.27 & 0.16 & 0.01 & -0.03 \\
\hline $\begin{array}{l}\text { Inlet partial pressure of } \\
\mathrm{CO}_{2}(x) \text { and total inlet } \\
\text { volumetric flow-rate }(z)\end{array}$ & $4.71 \%$ & $-0.39 \%$ & $+4.71 \%$ & 1 & 1 & $>30$ & 0.004 \\
\hline $\begin{array}{l}\text { Inlet partial pressure of } \\
\text { CO }(x) \text { and total inlet } \\
\text { volumetric flow-rate (z) }\end{array}$ & $33.51 \%$ & $-2.12 \%$ & $+33.51 \%$ & 0.81 & 1 & $>\mathbf{3 0}$ & 0.006 \\
\hline $\begin{array}{l}\text { Inlet partial pressure of } \\
\mathrm{H}_{2}(\mathrm{x}) \text { and total inlet } \\
\text { volumetric flow-rate }(\mathrm{z})\end{array}$ & $5.29 \%$ & $+5.29 \%$ & $-5.71 \%$ & 0.23 & 1 & $>30$ & 0.01 \\
\hline
\end{tabular}

The relative changes of different performance indicators (normalized outlet molar flow rate of methanol, yield of methanol based on total carbon and yield of methanol based on hydrogen), owing to the periodic input modulations, are calculated using the following generalized equation:

Rel. change $=\frac{P I_{P O}-P I_{S S}}{P I_{S S}} * 100(\%)$

where PI is the general notation for a performance indicator $\left(P I=\dot{n}_{\mathrm{CH}_{3} \mathrm{OH}}^{\text {norm }}, Y_{\mathrm{CH}_{3} \mathrm{OH}}^{\mathrm{totC}}\right.$ or $\left.Y_{\mathrm{CH}_{3} \mathrm{OH}}^{\text {totC }}\right)$. Based on the results presented in Table 2, it can be concluded that for all cases with simultaneous modulation of partial pressures of 2 reactants, although possible, the maximal potential improvements are negligible. On the other hand, for the cases with simultaneous modulation of partial pressure of one reactant and the inlet volumetric flow rate, some measurable improvements can be expected. The best case is obviously the one with simultaneous modulation of the inlet partial pressure of $\mathrm{CO}$ and inlet volumetric flow rate, with maximal predicted increase of the normalized outlet molar flow-rate of methanol of $33.51 \%$. This case will be presented in detail in the next section and some details for all other cases will be given in Appendix E. 


\subsection{Detailed results for simultaneous modulations of partial pressure of $\mathrm{CO}$ and}

\section{volumetric flow-rate}

Based on the results presented in Table 2, the periodic operation with simultaneous modulations of the inlet partial pressure of $\mathrm{CO}$ and volumetric flow-rate of the feed stream was chosen as the best scenario for methanol synthesis. In this section we present this case in more details.

In Figure 1, the optimal forcing parameters, i.e. forcing amplitudes of the inlet partial pressure of $\mathrm{CO}$ and inlet volumetric flow-rate, as well as the phase difference between the two modulated inputs which maximize the normalized outlet molar flow rate of methanol, are presented as functions of dimensionless forcing frequency.

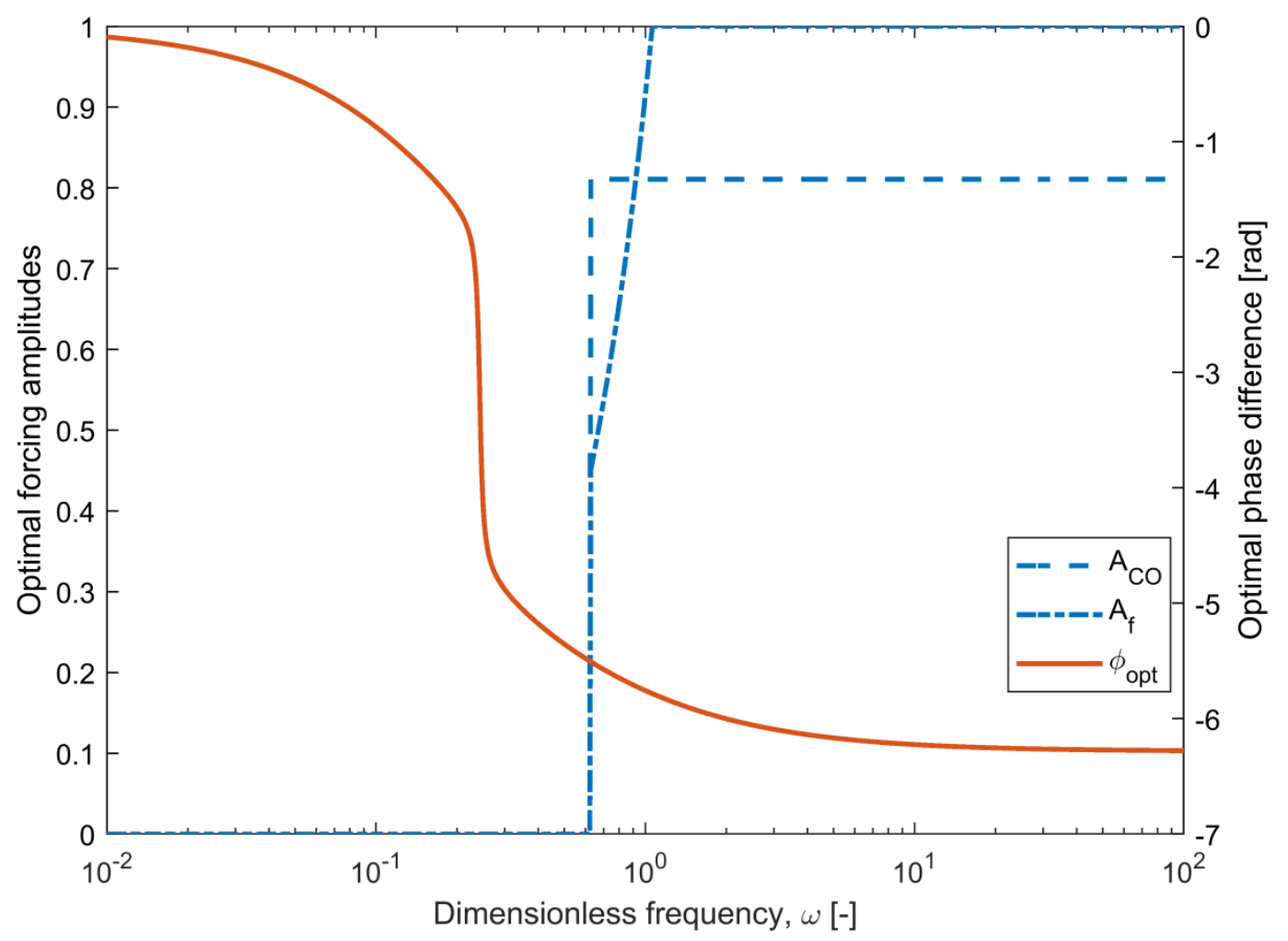

Figure 1. The optimal forcing parameters (forcing amplitudes and phase difference) which maximize the outlet molar flow-rate of methanol for simultaneous modulations of the CO partial pressure and flow-rate of the feed stream, vs. dimensionless forcing frequency

The ASO FRFs corresponding to the dimensionless outlet molar flow-rate of methanol, for single input modulations of the feed CO partial pressure and feed volumetric flow-rate, as well as the cross ASO term (Eq. 23) (calculated with the optimal phase difference between the two inputs, shown in Figure 1), vs. dimensionless forcing frequency, are presented in Figure 2. 


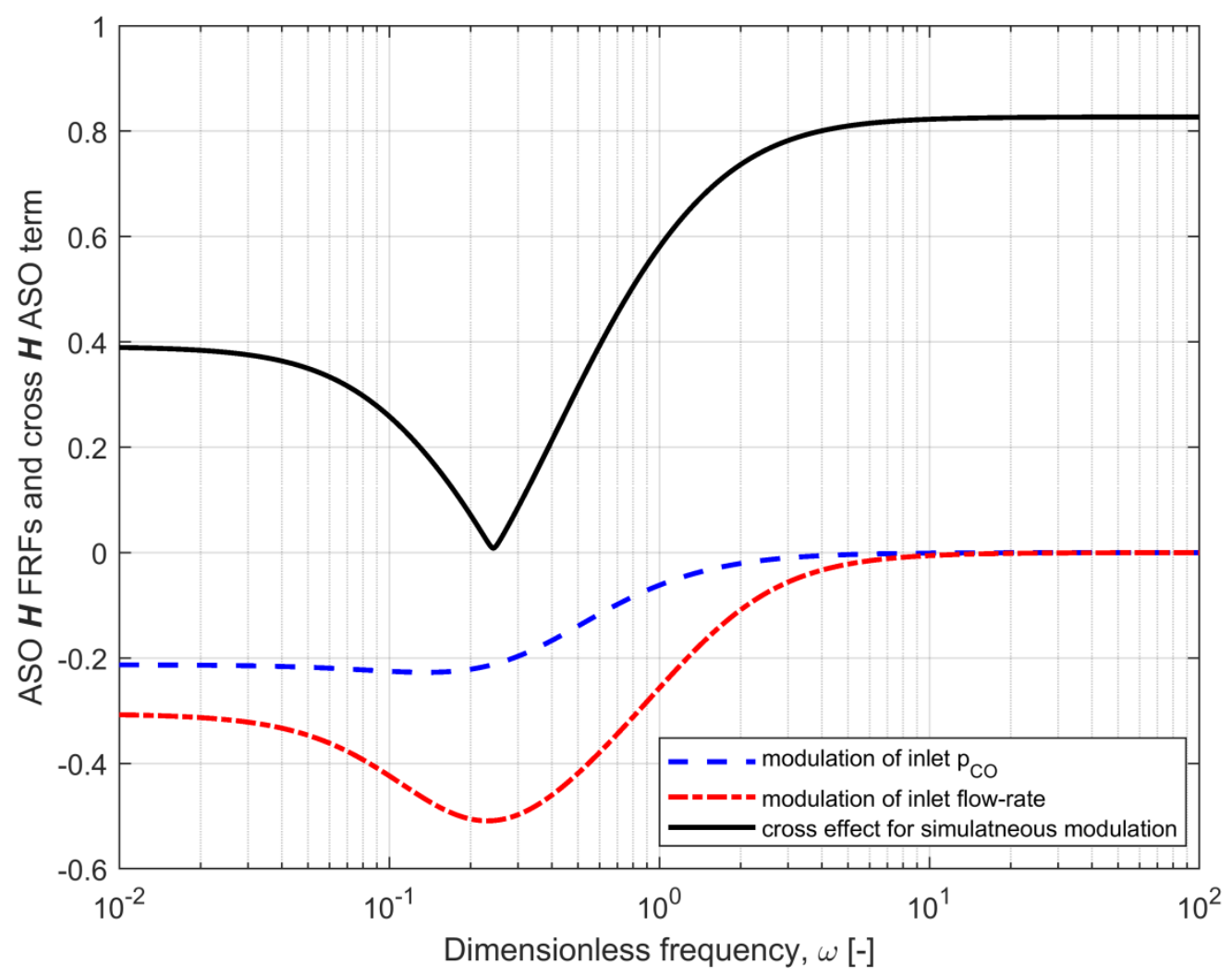

Figure 2. The ASO FRFs corresponding to the dimensionless methanol molar flow-rate for single input modulations of the inlet partial pressure of $\mathrm{CO}$ and inlet volumetric flow-rate and the cross ASO term vs. dimensionless forcing frequency

The normalized outlet molar flow-rate of methanol obtained for simultaneous modulation of inlet partial pressure of $\mathrm{CO}$ and volumetric flow rate with the optimal forcing parameters (shown in Figure 1) is presented in Figure 3, together with the corresponding optimal steady-state value. The corresponding yields of methanol based on total carbon and based on hydrogen, together with their steady-state values, are presented in Figure 4. 


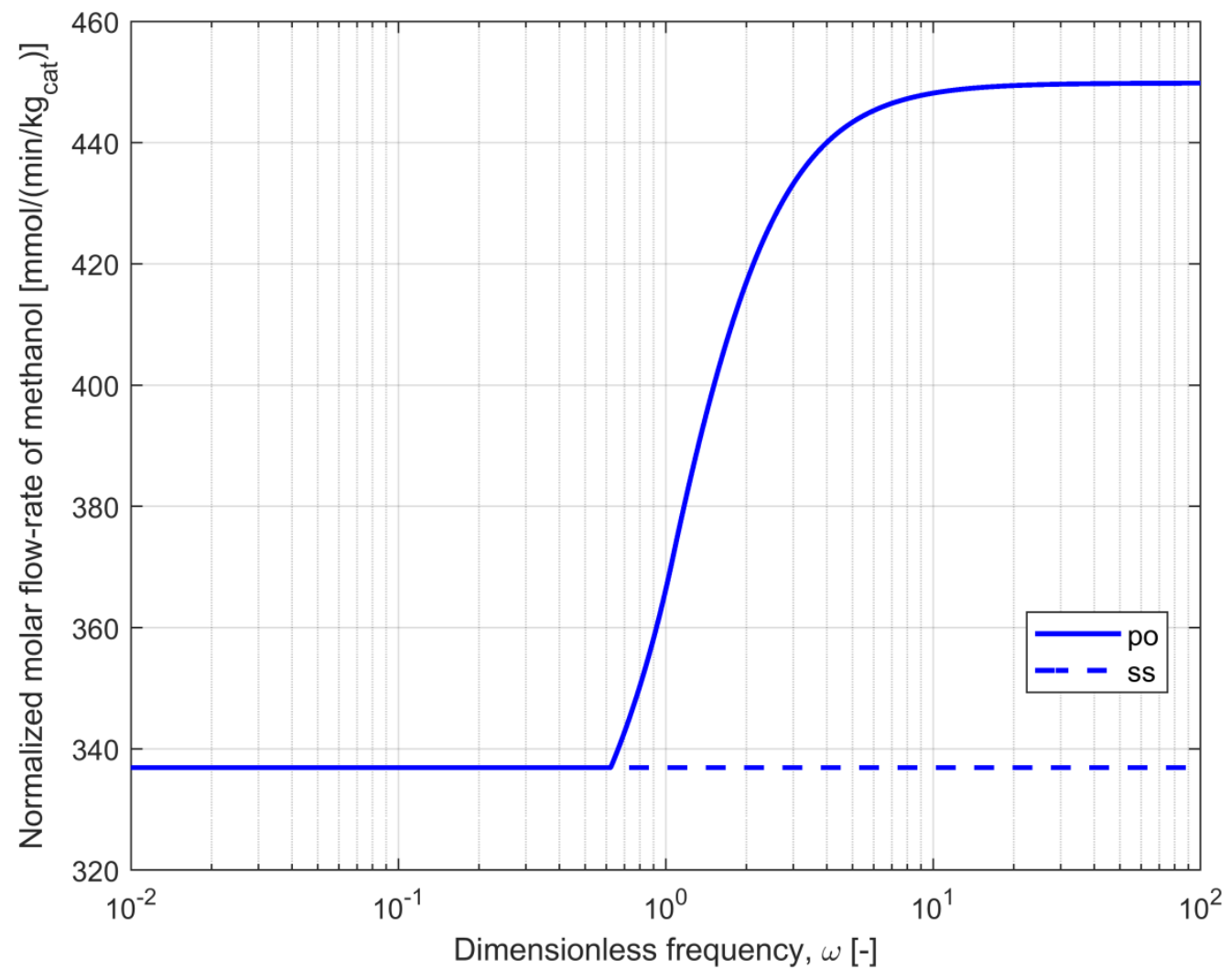

Figure 3. The normalized outlet molar flow-rate of methanol for optimal steady-state (ss) and periodic operation with simultaneous modulation of inlet partial pressure of $\mathrm{CO}$ and inlet volumetric flow-rate around the optimal steady-state with optimal forcing parameters (po) vs. dimensionless forcing frequency 


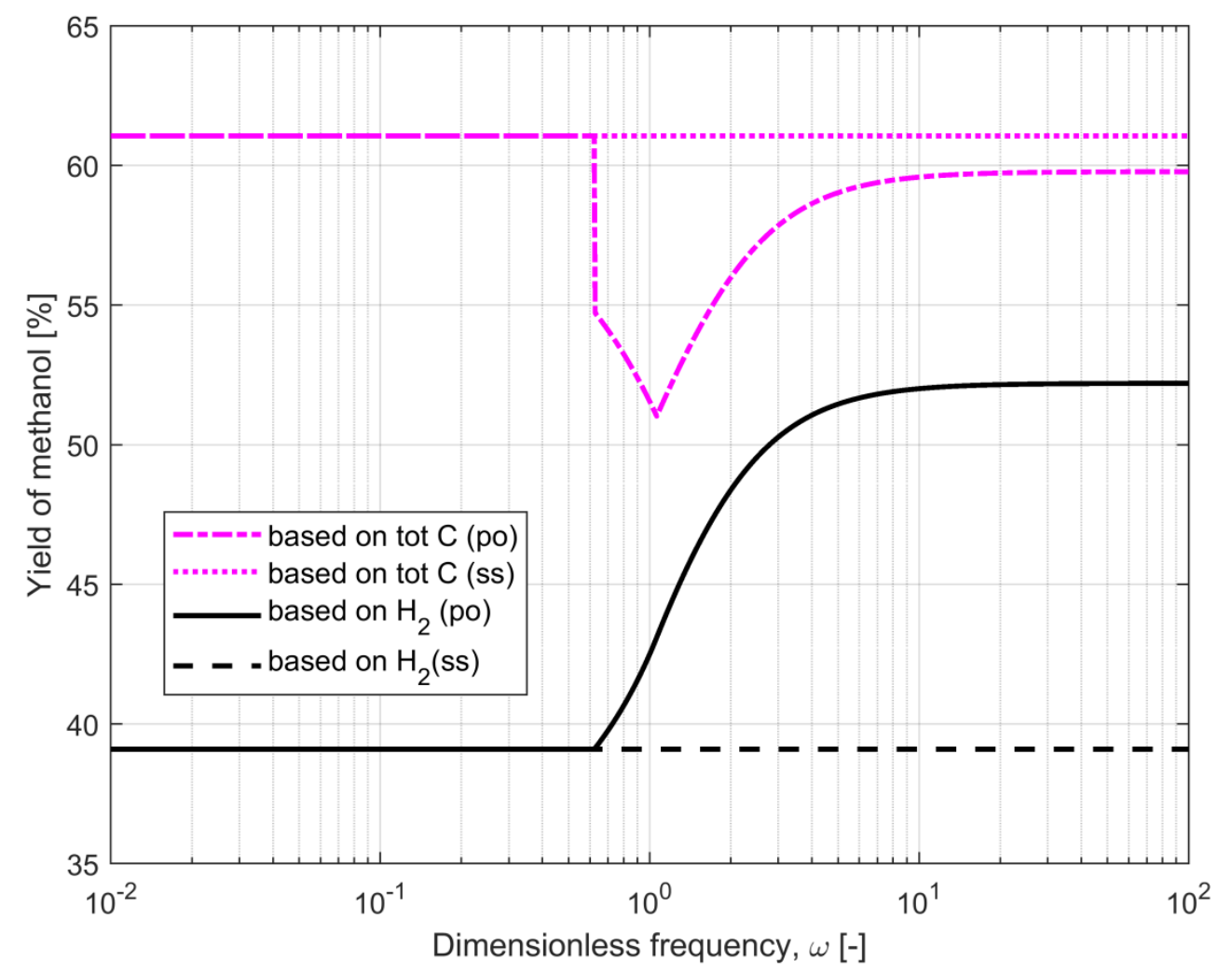

Figure 4 The yields of methanol based on total carbon and based on hydrogen for optimal steady-state (ss) and periodic operation with simultaneous modulation of inlet partial pressure of $\mathrm{CO}$ and inlet volumetric flow-rate (po) around the optimal steady-state with optimal forcing parameters (Figure 1), vs. dimensionless forcing frequency

Based on the simulation results presented in Figures 1-4, as well as in Table 2, the following conclusions could be drawn:

- $\quad$ Figure 1 shows that the optimal phase difference goes from 0 (for very low frequencies) to $-2 \pi$ (for high frequencies). The optimal inputs amplitudes are zero for all dimensionless frequencies lower than 0.62 (corresponding to period of oscillation of $\sim 900 \mathrm{~s}$ ), meaning that for lower frequencies it is not possible to find a periodic operation with simultaneous modulation of $\mathrm{CO}$ partial pressure and flow-rate that would be superior to the steady-state one. For dimensionless frequencies higher than 0.62 the optimal amplitudes rise sharply, reaching their maximal possible values ( 1 for the inlet flow-rate and 0.81 for the inlet CO partial pressure).

- Figure 2 shows that the ASO FRFs corresponding to the considered inputs are negative in the whole frequency-range, meaning that single input modulations of the inlet partial pressure of $\mathrm{CO}$ and inlet volumetric flow-rate would lead to decrease of the normalized outlet molar flow rate of methanol (as already shown in Part I of this paper). On the other hand, the cross effect of simultaneous modulation of these two inputs with optimal phase 
difference has a positive effect on the desired output (the cross ASO term is positive in whole frequency range). The overall effect of simultaneous modulation of those two inputs will depend on the input amplitudes and it will be desirable only if a set of input amplitudes can be found such that the positive effect of the cross contribution becomes predominant. According to the results presented in Figure 1, such set can be found only for $\omega>0.62$.

- The normalized methanol production, shown in Figure 3, is equal to the optimal steadystate value for $\omega<0.62$. For all frequencies $\omega>0.62$, the periodic operation with optimal amplitudes and phase difference is superior to the steady-state one. The highest increase or the normalized outlet molar flow rate of methanol is $33.51 \%$. Theoretically, the maximal value is obtained for infinite frequency, but practically it is reached already for $\omega \approx 30$ (corresponding to period of $18.7 \mathrm{~s}$ ). Increase of normalized outlet molar flow-rate of methanol of around $33 \%$ can be obtained already for the $\omega \approx 10$ (correspond to period of $56 \mathrm{~s})$.

- The corresponding yield of methanol based on hydrogen (Figure 4) completely follows the profile of methanol production, which is logical, taking into account its definition in Table 2. On the other hand, for $\omega>0.62$ the yield of methanol based on total carbon is lower than the corresponding optimal steady-state value. The explanation for this behaviour can be found in the fact that, for the that frequency range and the values of the forcing amplitudes and phase difference (Figure 1), the inlet molar flow-rate of CO (and total carbon) is higher than its corresponding steady state value (according to equation (?)). In order to find the optimal periodic operation which would satisfy all performance criteria, it would be best to use multi-objective optimization. This analysis and its results are shown in the next section.

\subsection{Multi-objective optimization}

In this work we use a recently developed methodology (Živković et al, 2020b) which combines the NFR method with standard multi-objective optimization techniques. In this methodology the objective functions are defined based on the time-average values of the outputs of interest, which are directly related to their DC components. Using the NFR approach, these DC components are approximated by algebraic expressions which are defined based on the corresponding ASO FRFs, input amplitudes and the phase difference between the modulated inputs. As a consequence, the computing time needed for the dynamic optimization of the forced periodic operation is of the same order of magnitude as the computing time needed for the steady-state optimization (Živković et al, 2020b) (much shorter than for classical numerical dynamic optimization). Also, all optimization parameters, i.e., the steady-state point and the forcing 
parameters (frequency, amplitudes, and phase difference), can be determined rapidly in one step. This enables finding an optimal periodic operation around a sub-optimal steady-state point which would be superior to any periodic operation around a previously chosen steady-state point (Živković et al, 2020b).

In the current study, we perform multi-objective optimization of a periodic operation with simultaneous modulations the CO partial pressure and volumetric flow-rate of the feed stream. Two objective functions are defined, the yield of methanol based on total carbon and the normalised methanol production:

$$
\begin{aligned}
& O F 1=\left(Y_{\mathrm{CH}_{3} \mathrm{OH}}^{\mathrm{totC}}\right)_{P O} \\
& O F 2=\left(\dot{n}_{\mathrm{CH}_{3} \mathrm{OH}}^{\text {norm }}\right)_{P O}
\end{aligned}
$$

By combining equations (24) and (25) with equation (19) and (27), both objective functions can be approximated by algebraic expressions of frequency, the input amplitudes and the phase difference between the inputs, as well as the steady-state partial variables.

$$
\begin{aligned}
& O F 1 \approx \frac{p_{\mathrm{CH}_{3} \mathrm{OH}, S} \dot{V}_{S}}{p_{C O 2,0, S} \dot{V}_{S}+p_{C O, 0, S} \dot{V}_{S}\left(1+\frac{A_{C O} A_{f}}{2} \cos (\varphi)\right)}\left(1+2\left(\frac{A_{C O}}{2}\right)^{2} H_{1,2,2}^{(2)}(\omega,-\omega)\right. \\
& \left.+2\left(\frac{A_{f}}{2}\right)^{2} H_{1,4,4}^{(2)}(\omega,-\omega)+2\left(\frac{A_{C O}}{2}\right)\left(\frac{A_{f}}{2}\right) H_{1,2,4}^{*(2)}(\omega, \varphi)\right) \\
& O F 2 \approx \frac{p_{C H_{3} O H, s} \dot{V}_{s}}{R T m_{c a t}}\left(1+2\left(\frac{A_{C O}}{2}\right)^{2} H_{1,2,2}^{(2)}(\omega,-\omega)+2\left(\frac{A_{f}}{2}\right)^{2} H_{1,4,4}^{(2)}(\omega,-\omega)\right. \\
& \left.+2\left(\frac{A_{C O}}{2}\right)\left(\frac{A_{f}}{2}\right) H_{1,2,4}^{*(2)}(\omega, \varphi)\right)
\end{aligned}
$$

In the current multi-objective optimization of the periodic operation the following optimization parameters were determined: inlet partial pressures of $\mathrm{CO}_{2}, \mathrm{CO}$, and $\mathrm{H}_{2}$ (corresponding to the steady-state point around which the periodic modulations should be performed), the forcing amplitudes of the CO partial pressure and volumetric flow-rate, the forcing frequency and the phase difference. The lower and upper bounds for the optimization variables, as well as defined constraints for the multi-objective optimization are given in Appendix F. The resulting Pareto front is shown. For comparison, the Pareto front obtained by multi-objective optimization of the 
steady-state operation, obtained in Part I (Appendix G) is also given in Figure 5. The data for each point of both Pareto fronts are given in Appendix F.

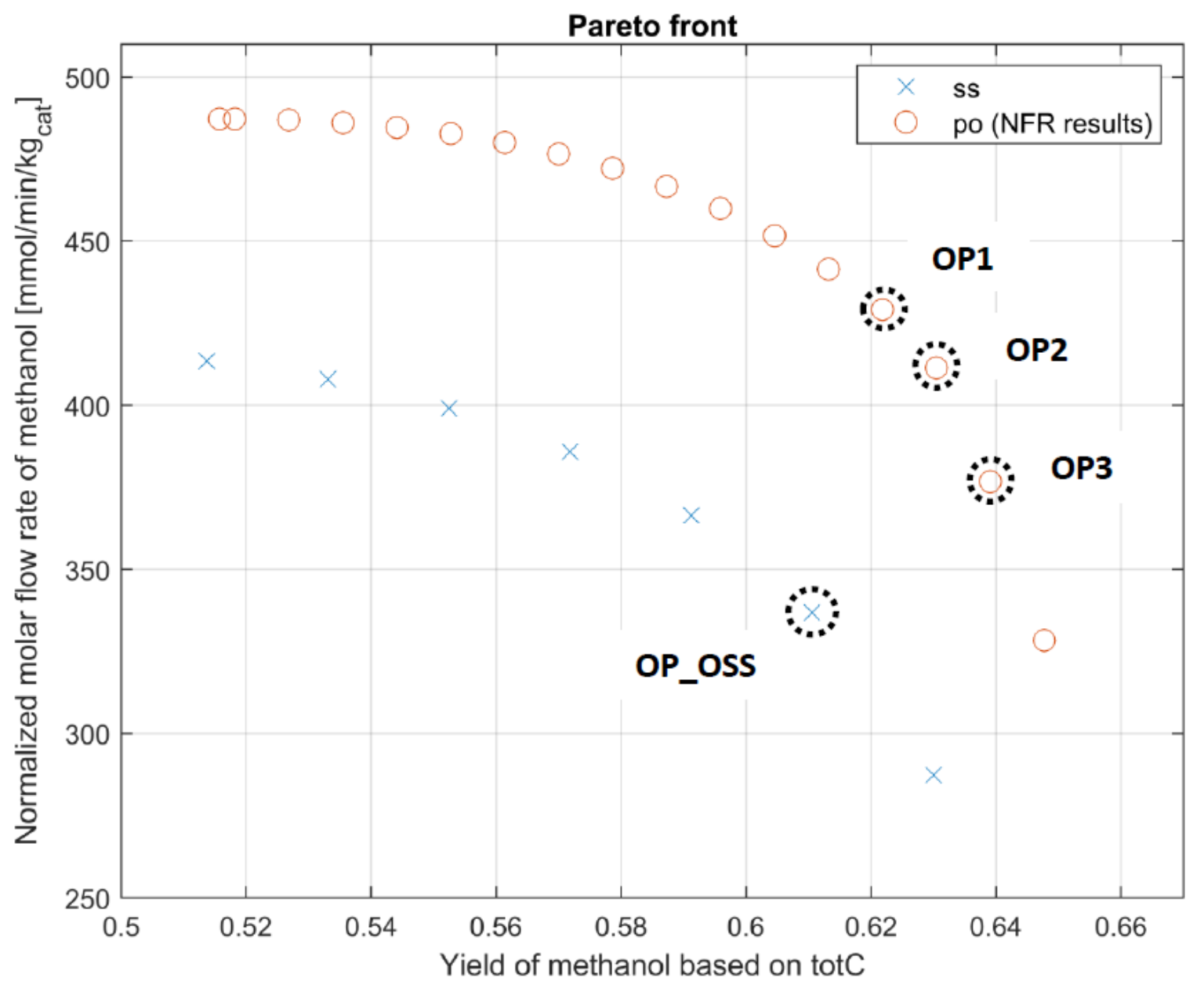

Figure 5 Pareto fronts for multi-objective optimization of Yield of methanol based on total C and normalized methanol production, for steady state (crosses) and periodic operation (circles)

For illustration, four operating points (OP) are selected and marked in Figure 5. The point OP_SS selected on the steady-state Pareto front (point no. 8 in Table F2) is actually the optimal steady-state point that was previously selected for analysis in both parts of this manuscript. Three operating points: OP1, OP2 and OP3 are also selected on the Pareto front for the periodic operation (points no. 16, 17 and 18 in Table F3).

The values of both objective functions corresponding to the four operation points chosen in Figure 5 (OP_OSS from the steady-state Pareto front and OP1, OP2 and OP3 from the periodic operation Pareto front) are given in Table 3. The relative changes of both objective functions between points OP1, OP2 and OP3, on one, and OP_OSS on the other hand, are also given. 
As the NFR method is essentially approximate, the values of the objective functions calculated using the results of numerical simulations for the same operation points are also given in Table 3 . Although the numerical simulation predictions show somewhat lower improvement than the NFR approximations, the agreement between the numerical and NFR results is very good (the error is around or less than $1.5 \%$ ).

Table 3 The normalized outlet molar flow rate of methanol and yield of methanol based on total carbon for the selected points from the Pareto fronts (Figure 5), based on NFR method and based on numerical simulation

\begin{tabular}{|c|c|c|c|c|c|c|c|c|}
\hline \multirow[t]{2}{*}{$\begin{array}{c}\text { Operating } \\
\text { point }\end{array}$} & \multicolumn{2}{|c|}{$\begin{array}{l}\text { Normalized outlet } \\
\text { molar flow-rate of } \\
\text { methanol } \\
{\left[\mathrm{mmol} / \mathrm{min} / \mathrm{kg}_{\text {cat }}\right]}\end{array}$} & \multicolumn{2}{|c|}{$\begin{array}{c}\text { Yield of methanol } \\
\text { based on total carbon } \\
{[\%]}\end{array}$} & \multicolumn{2}{|c|}{$\begin{array}{c}\text { Relative change of } \\
\text { normalized outlet molar } \\
\text { flow-rate of methanol }\end{array}$} & \multicolumn{2}{|c|}{$\begin{array}{l}\text { Relative change of } \\
\text { yield of methanol } \\
\text { based on total carbon }\end{array}$} \\
\hline & NFR & Num.Sim. & NFR & Num.Sim. & NFR & Num.Sim. & NFR & Num.Sim. \\
\hline OP_OSS & \multicolumn{2}{|c|}{336.9} & \multicolumn{2}{|c|}{61.06} & \multicolumn{2}{|c|}{ I } & \multicolumn{2}{|c|}{ I } \\
\hline OP1 & 428.96 & 422.04 & 62.18 & 61.18 & $+27.33 \%$ & $+25.27 \%$ & $+1.83 \%$ & $+0.20 \%$ \\
\hline OP2 & 411.20 & 405.34 & 63.04 & 62.15 & $+22.05 \%$ & $+20.31 \%$ & $+3.24 \%$ & $+1.79 \%$ \\
\hline OP3 & 376.80 & 373.05 & 63.91 & 63.27 & $+11.84 \%$ & $+10.73 \%$ & $+4.67 \%$ & $+3.62 \%$ \\
\hline
\end{tabular}

From the results presented in Figure 5 and Table 3 it can be concluded that multi-objective optimization enables finding operating points for which the increase of both objective functions is possible. For example, for the operation point OP2 it is possible to achieve increase of methanol production of $22.05 \%$ and increase of yield of methanol based on total carbon of $3.24 \%$. Those results are in good agreement with numerical simulation results presented also in Table 3. It should be noticed that the operating points chosen for comparison lay close to the right lower corner of the Pareto fronts. In this region, the increase of methanol production owing to periodic operation is more significant than the increase of the yield. Nevertheless, if operation points from the left upper corner would be chosen, the situation would be the opposite.

A rigorous numerical optimization based on the full nonlinear model will be presented in (Seidel et. al., 2021). 


\section{Conclusions}

In this paper, the NFR analysis was used in order to explore possible improvements of process performances owing to forced periodic operations of a well-mixed reactor in which heterogeneously catalysed methanol synthesis reactor takes, for 6 different cases of simultaneous modulations of two inputs. It was concluded that:

- For all six combinations of input modulations, simultaneous modulations of two inputs can result with improvement, even though the separate input modulations would lead to deterioration of process performances. The appropriate choice of the phase difference between the modulated inputs has a decisive role, but optimization of the input amplitudes is also necessary.

- For the case when an increase of normalized outlet molar flow-rate is set as the main indicator of improvement, for all cases of simultaneous modulation of partial pressures of two reactants the highest possible increase is less than $1 \%$. On the other hand, for simultaneous modulation of the partial pressures of $\mathrm{CO}_{2}$ or $\mathrm{H}_{2}$ and inlet volumetric flowrate, the maximal increase is around 5\%. The highest increase of the normalized outlet molar flow rate of methanol of $33.5 \%$ is predicted for the case of simultaneous modulation of the inlet partial pressure of $\mathrm{CO}$ and inlet volumetric flow-rate, with optimal forcing parameters.

- The NFR analysis also enables fast and easy multi-objective optimization. Multiobjective optimization with two objective functions: yield of methanol based on total carbon and normalised methanol production, which was performed for the most promising case of simultaneous modulations of $\mathrm{CO}$ partial pressure and volumetric flow rate, led to operating points superior to the steady-state operation regarding both indicators of improvement.

- The NFR method was proven as a useful and powerful theoretical tool for analysis, design and optimization of periodic operations, even for the complex case of methanol synthesis reactor.

The theoretical results of the NFR analysis, presented in this work, were used as the basis for full numerical optimization of periodically operated methanol synthesis reactor (Seidel et al, 2021). These results will also serve for planning the experimental investigation in a lab-scale Berty type reactor which is planned for near future. 


\section{Nomenclature}

$A$

E

$G_{y, x, x, \ldots x}^{(n)}(\omega 1, \ldots, \omega 2)$

$G_{y, x, z}^{(2)}(\omega,-\omega)$

$\Delta G[\mathrm{~J} / \mathrm{mol}]$

$H_{i, x, x}^{(2)}(\omega,-\omega)$

$H_{i, x, z}^{(2)}(\omega,-\omega)$ forcing amplitude of input modulation

auxiliary parameters for catalyst dynamic equation in dimensionless form

cross ASO FRF which correlates the output $y$ to modulated inputs $x$ and $z$

Gibbs free energy

ASO FRF which correlates the outlet molar flow-rate of component $i$ to modulated input $x$

cross ASO FRF which correlates the outlet molar flow-rate of component $i$ to modulated inputs $x$ and $z$

Jacobian matrix

$k_{j}$

reaction rate constant $\left(j=1\right.$ for $\mathrm{CO}$ hydrogenation, $j=2$ for $\mathrm{CO}_{2}$ hydrogenation, $j=3$ for RWGS)

$k_{1}^{+}, k_{2}^{+}\left[\mathrm{s}^{-1}\right]$

reaction rate constant for oxidation-reduction of catalyst

$K_{i}$ adsorption constant

$K_{1}, K_{2}$

equilibrium constants for oxidation-reduction of catalyst

$K_{P i}\left[\mathrm{bar}^{-2}\right]$

reaction rate constant for $(i=1) \mathrm{CO}$ or $(i=2) \mathrm{CO}_{2}$ hydrogenation

$K_{P 3}[-]$

reaction rate constant for RWGS

$m_{\text {cat }}[\mathrm{kg}]$

mass of catalyst

$\dot{n}[\mathrm{~mol} / \mathrm{s} ; \mathrm{mmol} / \mathrm{min}]$

molar flow rate

$\dot{n}^{\text {norm }}\left[\mathrm{mmol} / \mathrm{min} / \mathrm{kg}_{\text {cat }}\right]$

normalized molar flow rate (per unit of mass of catalyst)

$\dot{N}$

dimensionless molar flow rate

$p$ [bar]

total pressure

$p_{i}[\mathrm{bar}]$

partial pressure of component $i(i=1, \ldots, 6)$

$P_{i}[\mathrm{bar}]$

dimensionless partial pressure of component $i(i=1, \ldots, 6)$

$q_{\text {sat }}[\mathrm{mol} / \mathrm{kg}]$

specific amount of surface centres

$q, Q, \vartheta, U, s, S$

Taylor series coefficients for reaction rates

$R[\mathrm{~J} / \mathrm{mol} / \mathrm{K}]$

gas constant 
component $\left(i=1\right.$ for $\mathrm{CH}_{3} \mathrm{OH}, i=2$ for $\mathrm{CO}_{2}, i=3$ for $\mathrm{CO}, i=4$ for $\mathrm{H}_{2}, i=5$ for $\mathrm{H}_{2} \mathrm{O}$, $i=6$ for $\mathrm{N}_{2}$ )

modulation of total inlet volumetric flow rate

$\mathrm{H}_{2}$ modulation of partial pressure of $\mathrm{H}_{2}$ in feed stream

$j$ reaction $\left(j=1\right.$ for $\mathrm{CO}$ hydrogenation, $j=2$ for $\mathrm{CO}_{2}$ hydrogenation, $j=3$ for RWGS)

feed stream

PO, po periodic operation

SS,ss steady-state operation

mean mean value for periodic operation

$\mathrm{N}_{2} \quad$ modulation of partial pressure of $\mathrm{N}_{2}$ in feed stream

ref referent value

$s \quad$ steady-state

tot $C \quad$ total carbon

\section{Superscripts}

$\mathrm{H}_{2} \quad$ based on hydrogen

$\max \quad$ maximal value

totC based on total carbon

* $\quad$ reduced surface centre

$\odot \quad$ oxidized surface centre

$\otimes \quad$ surface centre for hydrogen

Abbreviations

$\mathrm{AC}$

Active centres on catalyst surface

ASO

Asymmetrical Second Order

FRF

Frequency Response Functions

NFR

Nonlinear Frequency Response

OP

Operating point

PI

Performance Indicator

RWGS

Reverse water-gas shift 


\section{Acknowledgment}

This work is supported under the Priority Programme 2080 of the German Research Foundation DFG 'Catalysts and Reactors under Dynamic Operating Conditions for Energy Storage and Conversion' within the project 'Analysis of forced periodic operation of chemical reactors considering methanol synthesis as an example' under grants PE 2915/1-1, K1 417/6-1, SE 586/24-1.The engagement of Prof. Menka Petkovska was supported by the Ministry of Education, Science and Technological Development of the Republic of Serbia (Contract No.45103-9/2021-14/200135).

\section{Appendix}

\section{Appendix A The definitions of dimensionless variables}

Table A1 The definitions of dimensionless variables

Dimensionless variables Definitions

Partial pressure of component $i$

$$
P_{i}=\frac{p_{i}-p_{i, s}}{p_{i, s}}, i=1, \ldots 6
$$

Partial pressure of component $i$ in the inlet stream $\quad P_{i, 0}=\frac{p_{i, 0}-p_{i 0, s}}{p_{i 0, s}}, i=1, \ldots 6$

Time

$$
\tau=\frac{t}{\tau_{0, s}}=\frac{t}{V_{G} / \dot{V}_{0, s}}
$$

Fraction of reduced centers on the catalyst surface

$$
\Phi=\frac{\phi-\phi_{s}}{\phi_{s}}
$$

Volumetric flow-rate of the inlet stream

$$
v_{0}=\frac{\dot{V}_{0}-\dot{V}_{0, s}}{\dot{V}_{0, s}}
$$

Volumetric flow-rate of the outlet stream

$$
\mathrm{v}=\frac{\dot{V}-\dot{V}_{s}}{\dot{V}_{s}}
$$

Frequency

$$
\omega=\omega_{d} \tau_{0, s}
$$

The dimensionless frequency $(\omega)$ is defined by using the residence time in steady-state calculated based of inlet volumetric flow-rate, defined as:

$\tau_{0, s}=\frac{V_{G}}{\dot{V}_{0, s}}$ 


\section{Appendix B The forcing amplitude of inert for simultaneous modulation of partial pressures of two reactants in the feed stream}

In order to assure that the total pressure in reactor is constant for simultaneous modulation of partial pressures of two reactants in the feed stream, the inlet pressure of inert $\left(\mathrm{N}_{2}\right)$ has to be modulated as follows:

$P_{N_{2}, 0}=A_{N_{2}}^{(1)} \cos (\omega \tau-\pi)+A_{N_{2}}^{(2)} \cos (\omega \tau-\pi+\varphi)$

or presented as

$P_{N_{2}, 0}=A_{N_{2}}^{t o t} \cos (\omega \tau-\pi+\sigma)$

where $A_{N_{2}}^{\text {tot }}$ is forcing amplitude for partial pressure of inert $\left(\mathrm{N}_{2}\right)$ and $\sigma$ is phase difference

$A_{N_{2}}^{\text {tot }}=\sqrt{\left(A_{N_{2}}^{(1)}\right)^{2}+2 A_{N_{2}}^{(1)} A_{N_{2}}^{(2)} \cos (\varphi)+\left(A_{N_{2}}^{(2)}\right)^{2}}$

$\sigma=\arctan \left(\frac{A_{N_{2}}^{(2)} \sin (\varphi)}{A_{N_{2}}^{(1)}+A_{N_{2}}^{(2)} \cos (\varphi)}\right)$

The $A_{N_{2}}^{(1)}, A_{N_{2}}^{(2)}$ and $A_{N_{2}}^{\text {tot }}$, have to satisfy two equalities and one nonequality

$A_{N_{2}}^{(1)}=\frac{y_{z, 0, s}}{y_{6,0, s}} A_{x} \quad A_{N_{2}}^{(2)}=\frac{y_{z, 0, s}}{y_{6,0, s}} A_{z}$

$A_{N_{2}}^{\text {tot }} \leq 1$

in order to assure that total pressure is constant.

\section{Appendix C The forcing amplitude of inert for simultaneous modulation of partial} pressure of one reactant and volumetric flow-rate of the feed stream

In this case, the partial pressure of inert $\left(\mathrm{N}_{2}\right)$ in feed stream should be modulated out-of-phase to partial pressure of reactant which is modulated, as follows

$P_{N_{2}, 0}=A_{N_{2}} \cos (\omega \tau-\pi)$

where the forcing amplitude of inert can be evaluated from following

$A_{N_{2}}=\frac{y_{x, 0,5}}{y_{6,0, s}} \cdot A_{x}$

Appendix D Auxiliary functions used in matrix equations for derivation of $G$ cross asymmetrical second order FRFs

The auxiliary functions $\Lambda$ are defined as follows 


$$
\begin{aligned}
\Lambda_{i, x, z}=-\frac{\dot{V}_{s}}{\dot{V}_{0, s}}[ & \left.G_{i, x}^{(1)}(\omega) G_{7, z}^{(1)}(-\omega)+G_{i, z}^{(1)}(-\omega) G_{7, x}^{(1)}(\omega)\right] \\
& +\frac{R T}{p_{i, s} \dot{V}_{0, s}} m_{c a t}\left[\sum _ { l = 1 } ^ { 6 } \sum _ { k = l } ^ { 6 } ( v _ { i , 1 } Q _ { l k } + v _ { i , 2 } U _ { l k } + v _ { i , 3 } S _ { l k } ) \left(G_{l, x}^{(1)}(\omega) G_{k, z}^{(1)}(-\omega)\right.\right. \\
& \left.\left.+G_{l, z}^{(1)}(-\omega) G_{k, x}^{(1)}(\omega)\right)\right]
\end{aligned}
$$

$$
(i=1, \ldots, 5 ; x=1, z=2 ; x=1, z=3 ; x=2, z=3)
$$

$$
\begin{aligned}
\Lambda_{i, x, z}=\frac{p_{i, 0, s}}{p_{i, s}}- & \frac{\dot{V}_{s}}{\dot{V}_{0, s}}\left[G_{i, x}^{(1)}(\omega) G_{7, z}^{(1)}(-\omega)+G_{i, z}^{(1)}(-\omega) G_{7, x}^{(1)}(\omega)\right] \\
& +\frac{R T}{p_{i, s} \dot{V}_{0, s}} m_{c a t}\left[\sum _ { l = 1 } ^ { 6 } \sum _ { k = l } ^ { 6 } ( v _ { i , 1 } Q _ { l k } + v _ { i , 2 } U _ { l k } + v _ { i , 3 } S _ { l k } ) \left(G_{l, x}^{(1)}(\omega) G_{k, z}^{(1)}(-\omega)\right.\right. \\
& \left.\left.+G_{l, z}^{(1)}(-\omega) G_{k, x}^{(1)}(\omega)\right)\right]
\end{aligned}
$$

$(i=1, \ldots, 5 ; x=1, z=4 ; x=2, z=4 ; x=3, z=4)$

$$
\begin{aligned}
\Lambda_{6, x, z}=\left[-E_{2}\right] & \left(G_{2, x}^{(1)}(\omega) G_{6, z}^{(1)}(-\omega)+G_{2, z}^{(1)}(-\omega) G_{6, x}^{(1)}(\omega)\right) \\
& +\left[-E_{1}\right]\left(G_{3, x}^{(1)}(\omega) G_{6, z}^{(1)}(-\omega)+G_{3, z}^{(1)}(-\omega) G_{6, x}^{(1)}(\omega)\right) \\
& +\left[-E_{3}\right]\left(G_{4, x}^{(1)}(\omega) G_{6, z}^{(1)}(-\omega)+G_{4, z}^{(1)}(-\omega) G_{6, x}^{(1)}(\omega)\right) \\
& +\left[-E_{4}\right]\left(G_{5, x}^{(1)}(\omega) G_{6, z}^{(1)}(-\omega)+G_{5, z}^{(1)}(-\omega) G_{6, x}^{(1)}(\omega)\right)
\end{aligned}
$$

$(x=k, z=k+1, \mathrm{k}+2, \mathrm{k}+3(k=1, \ldots, 3$ and $z \leq 4))$

$\Lambda_{7, \mathrm{x}, \mathrm{Z}}=m_{c a t} \sum_{i=1}^{5}\left[\sum_{l=1}^{6} \sum_{k=l}^{6}\left(v_{i, 1} Q_{l k}+v_{i, 2} U_{l k}+v_{i, 3} S_{l k}\right)\left(G_{l, x}^{(1)}(\omega) G_{k, z}^{(1)}(-\omega)+G_{l, z}^{(1)}(-\omega) G_{k, x}^{(1)}(\omega)\right)\right]$

$(x=k, z=k+1, \mathrm{k}+2, \mathrm{k}+3(k=1, \ldots, 3$ and $z \leq 4))$ 
Appendix E Results for simultaneous modulation of two inputs (partial pressures $\left(\mathrm{CO}_{2} \&\right.$ $\left.\mathrm{CO}, \mathrm{CO}_{2} \& \mathrm{H}_{2}, \mathrm{CO \&} \mathrm{H}_{2}\right)$ and partial pressure of one reactant $\left(\mathrm{CO}_{2}\right.$ or $\left.\mathrm{H}_{2}\right)$ and inlet volumetric flow-rate)

Appendix E1 Simultaneous modulation of partial pressures of $\mathrm{CO}_{2}$ and $\mathrm{CO}$ in the feed stream

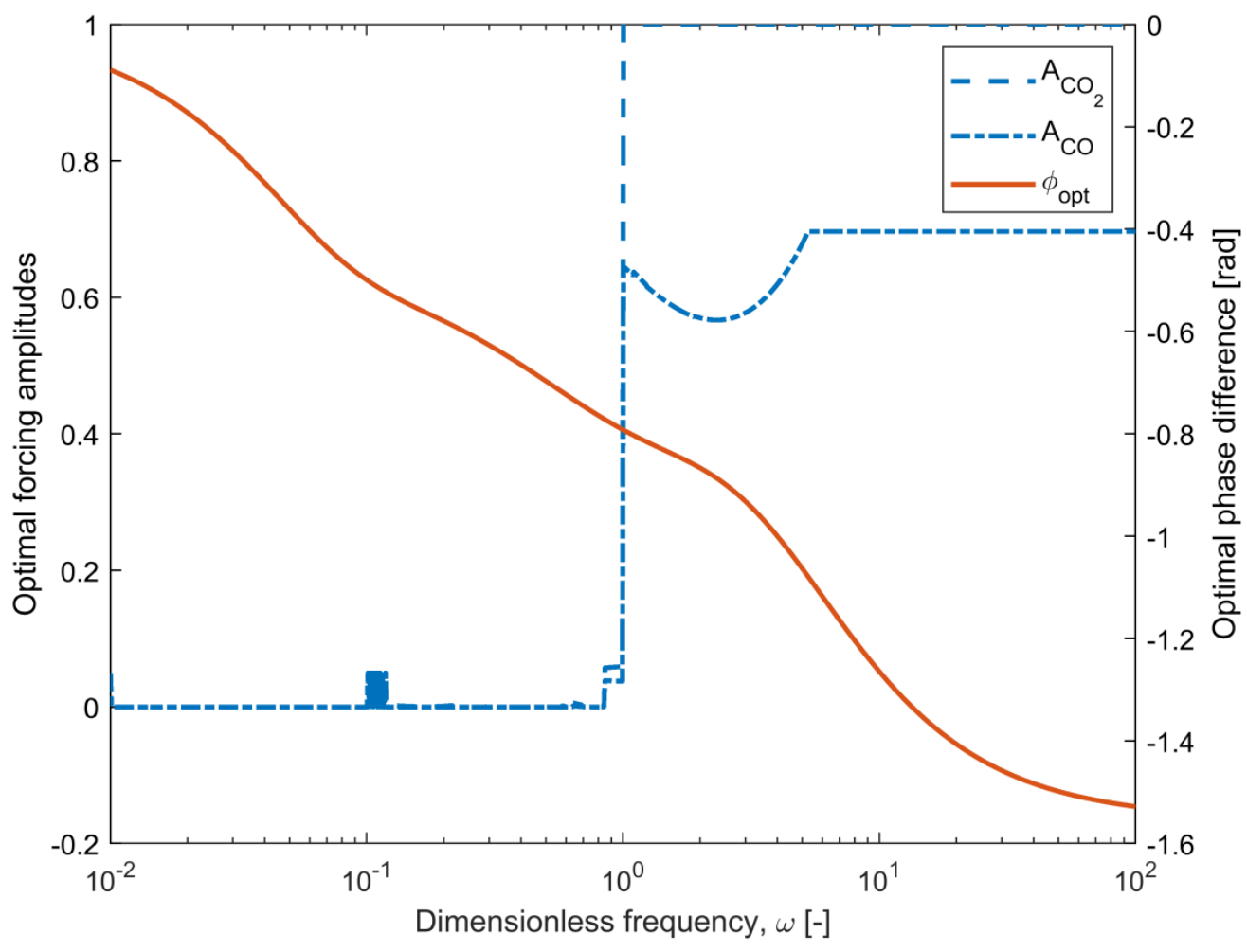

Figure E1.1 The optimal forcing parameters (forcing amplitudes and phase difference between the modulated inputs (partial pressures of $\mathrm{CO}_{2}$ and $\mathrm{CO}$ )) which maximize the normalized outlet molar flow-rate of methanol, vs. dimensionless forcing frequency 


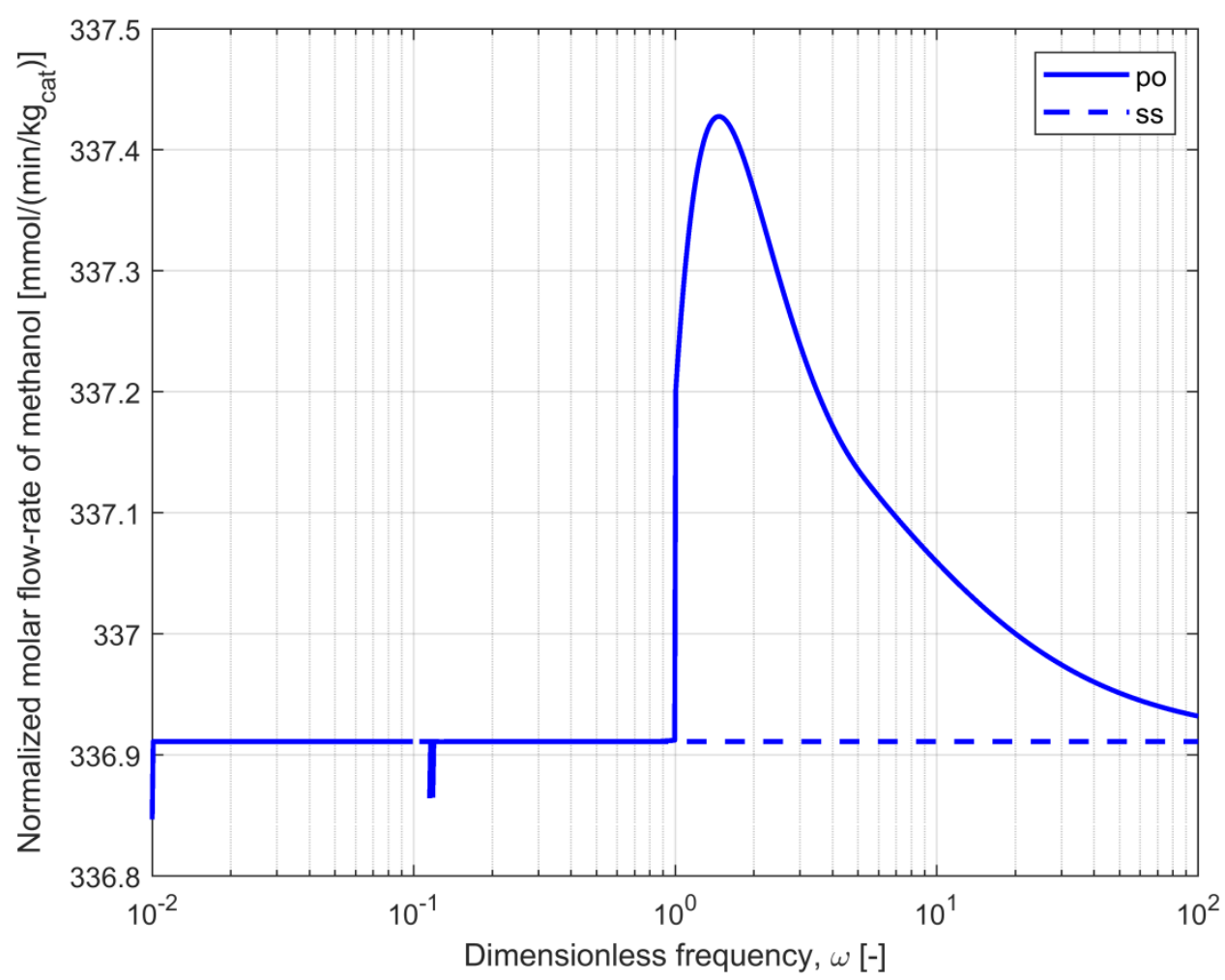

Figure E1.2 The normalized outlet molar flow-rate of methanol for steady-state and for simultaneous modulation of inlet partial pressures of $\mathrm{CO}_{2}$ and $\mathrm{CO}$ around the optimal steadystate modulated using optimal forcing parameters (forcing amplitudes and phase difference, Figure E1.1) vs. dimensionless forcing frequency. 
Appendix E2 Simultaneous modulation of partial pressures of $\mathrm{CO}_{2}$ and $\mathrm{H}_{2}$ in the feed stream

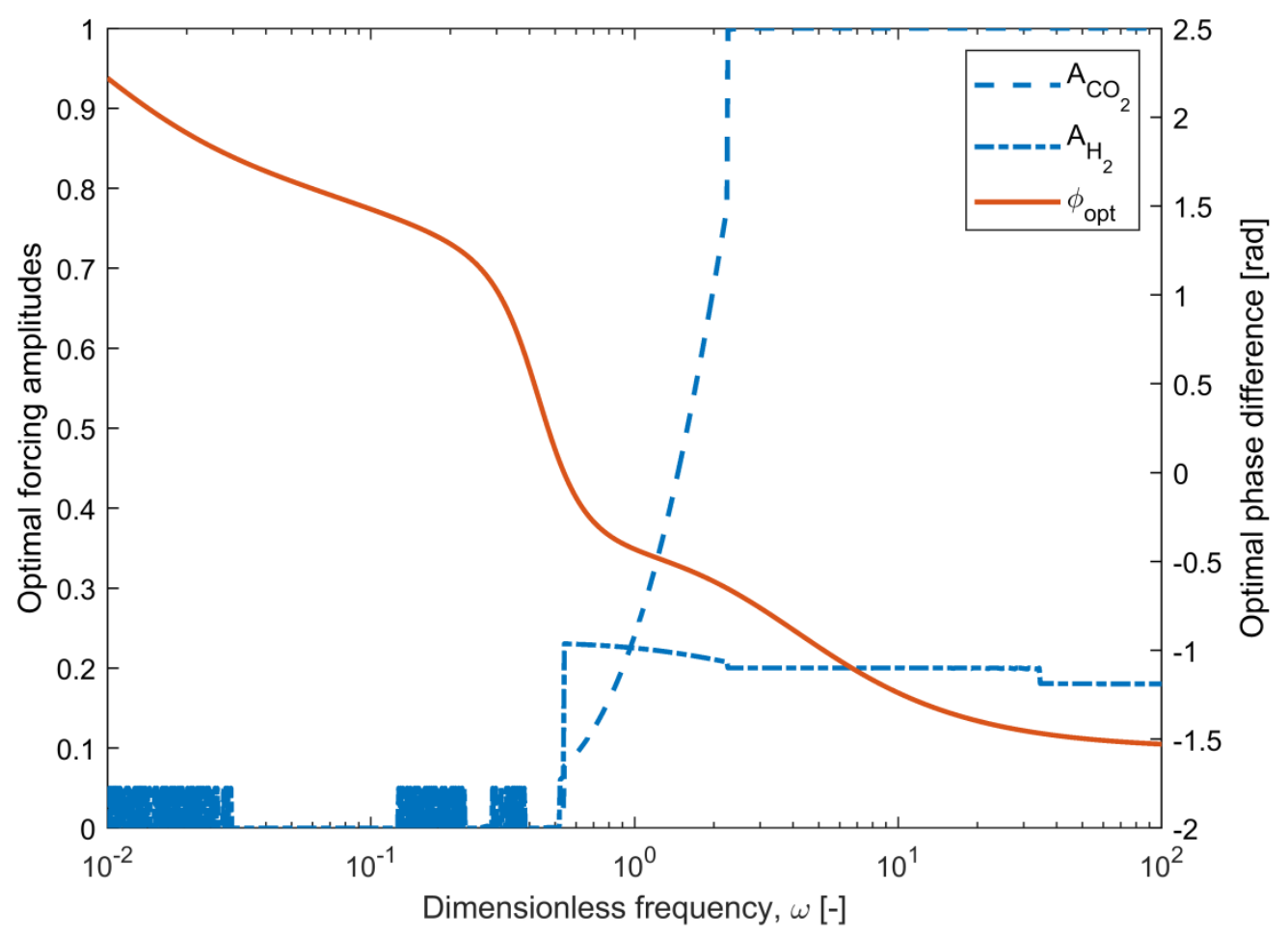

Figure E2.1 The optimal forcing parameters (forcing amplitudes and phase difference between the modulated inputs (partial pressures of $\mathrm{CO}_{2}$ and $\mathrm{H}_{2}$ )) which maximize the normalized outlet molar flow-rate of methanol, vs. dimensionless forcing frequency 


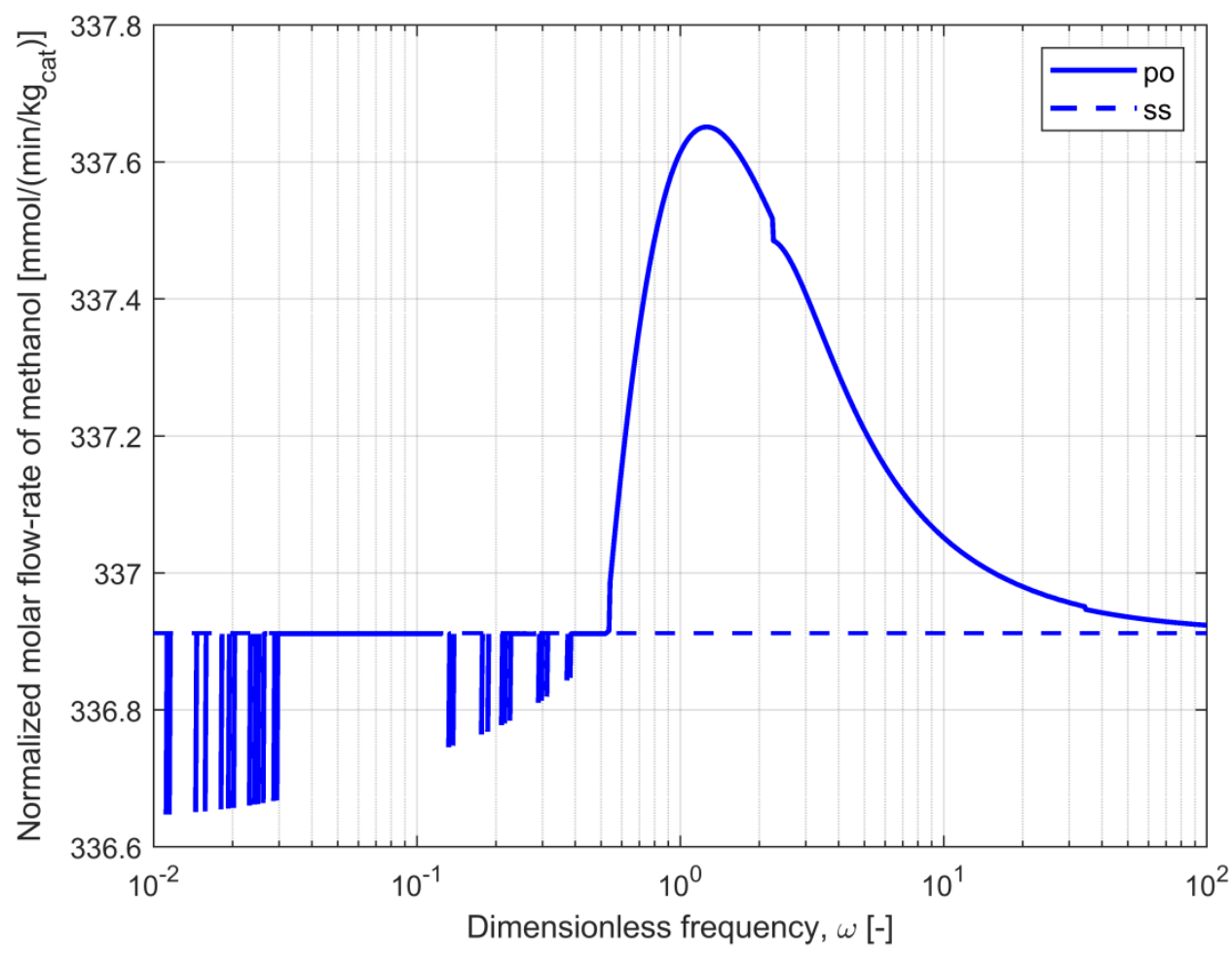

Figure E2.2 The normalized outlet molar flow-rate of methanol for steady-state and for simultaneous modulation of inlet partial pressures of $\mathrm{CO}_{2}$ and $\mathrm{H}_{2}$ around the optimal steady-state modulated using optimal forcing parameters (forcing amplitudes and phase difference, Figure E2.1) vs. dimensionless forcing frequency. 
Appendix E3 Simultaneous modulation of partial pressures of $\mathrm{CO}$ and $\mathrm{H}_{2}$ in the feed stream

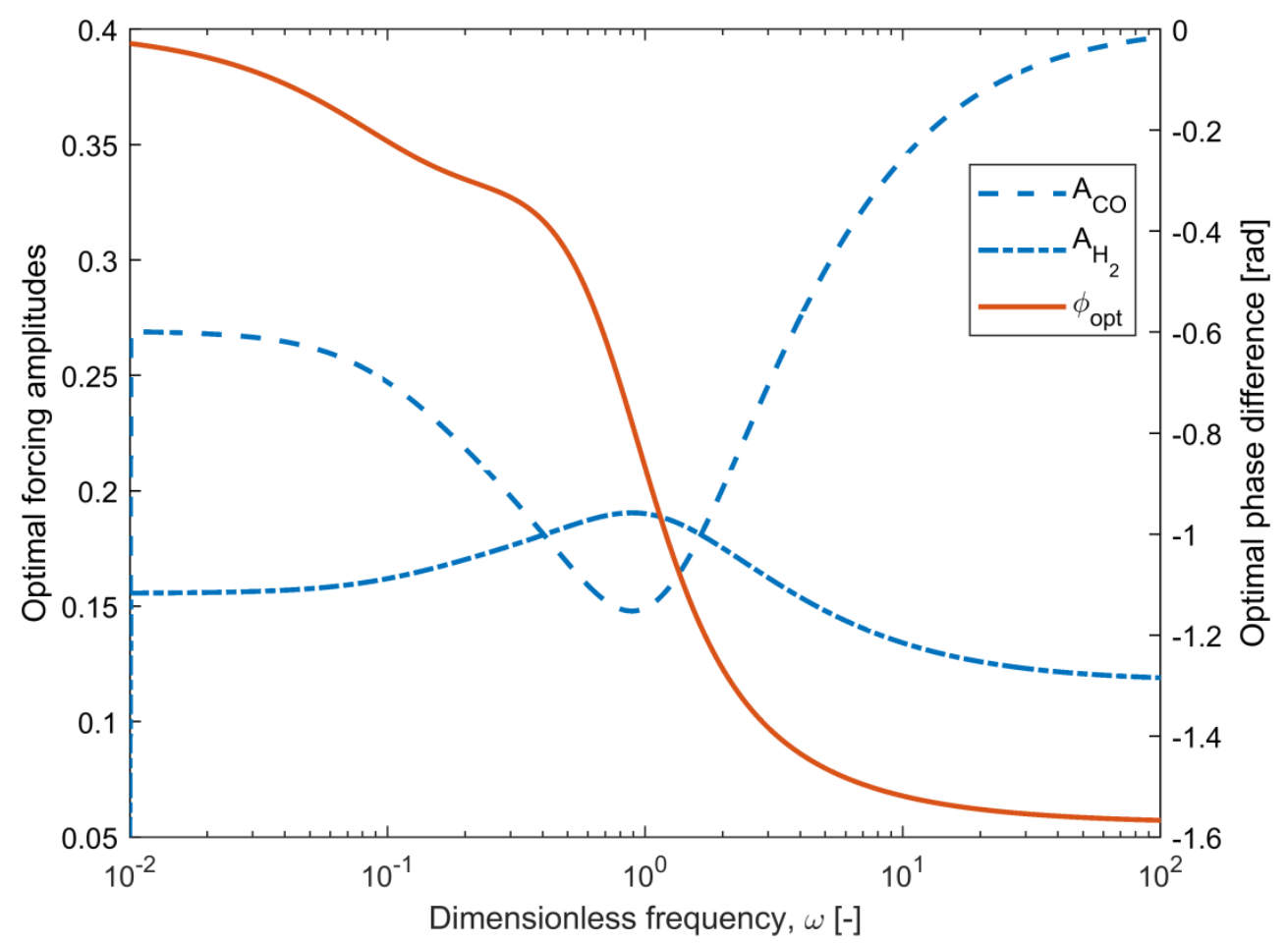

Figure E3.1 The optimal forcing parameters (forcing amplitudes and phase difference between the modulated inputs (partial pressures of $\mathrm{CO}$ and $\mathrm{H}_{2}$ )) which maximize the normalized outlet molar flow-rate of methanol, vs. dimensionless forcing frequency 


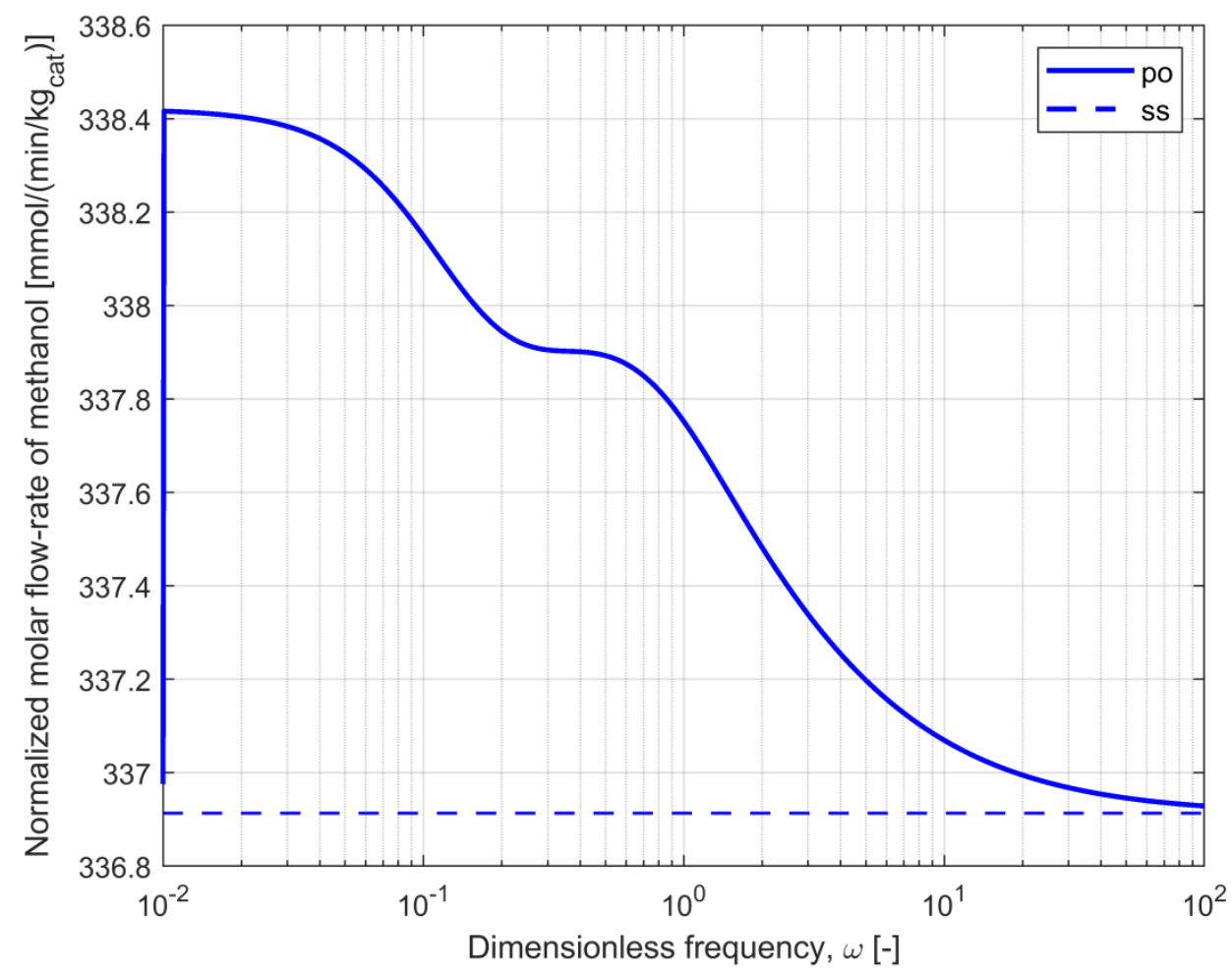

Figure E3.2 The normalized outlet molar flow-rate of methanol for steady-state and for simultaneous modulation of inlet partial pressures of $\mathrm{CO}$ and $\mathrm{H}_{2}$ around the optimal steady-state modulated using optimal forcing parameters (forcing amplitudes and phase difference, Figure E3.1) vs. dimensionless forcing frequency. 
Appendix E4 Simultaneous modulation of partial pressures of $\mathrm{CO}_{2}$ in the feed stream and inlet volumetric flow-rate

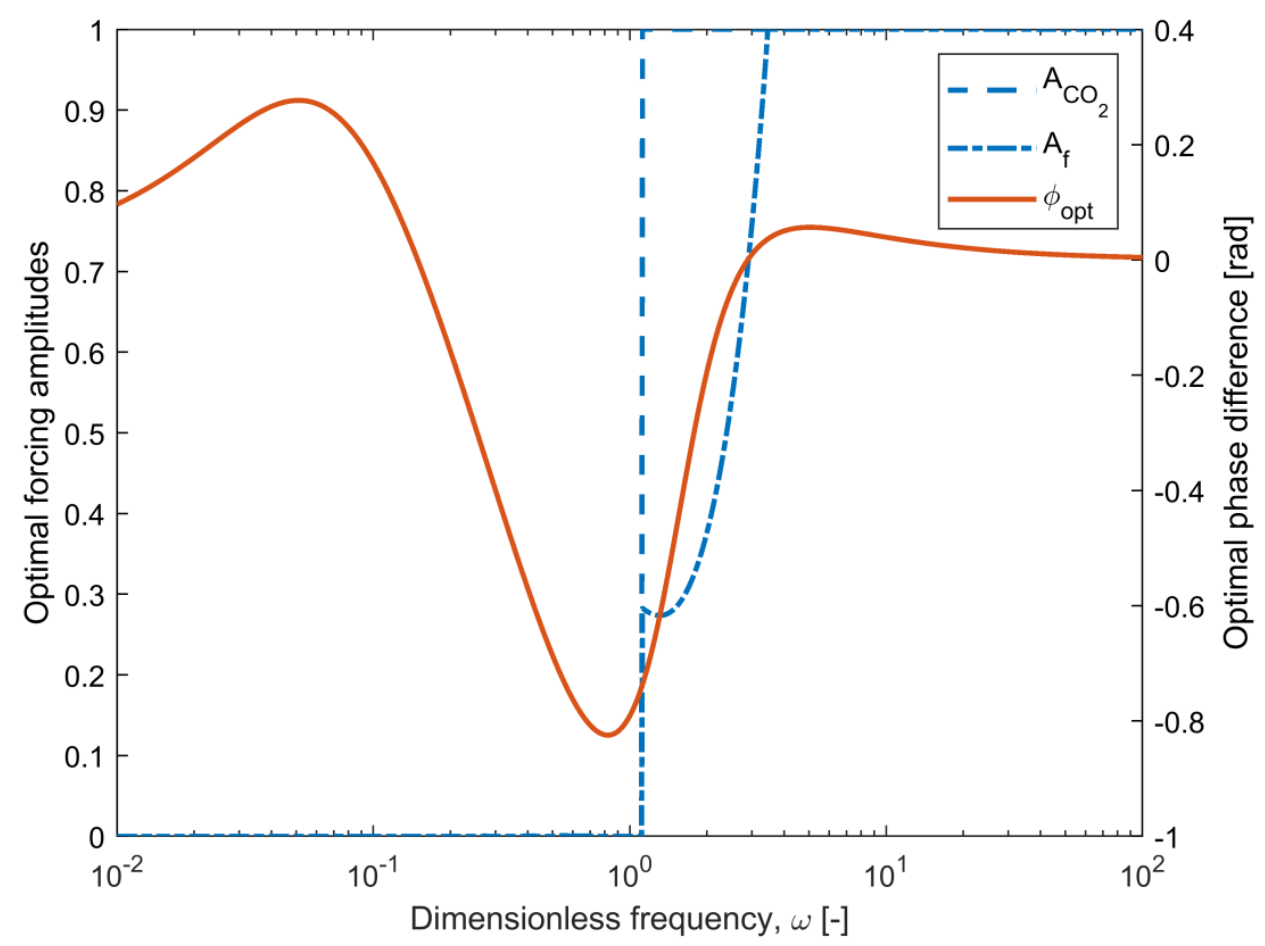

Figure E4.1 The optimal forcing parameters (forcing amplitudes and phase difference between the modulated inputs (partial pressure of $\mathrm{CO}_{2}$ and inlet volumetric flow-rate)) which maximize the normalized outlet molar flow-rate of methanol, vs. dimensionless forcing frequency

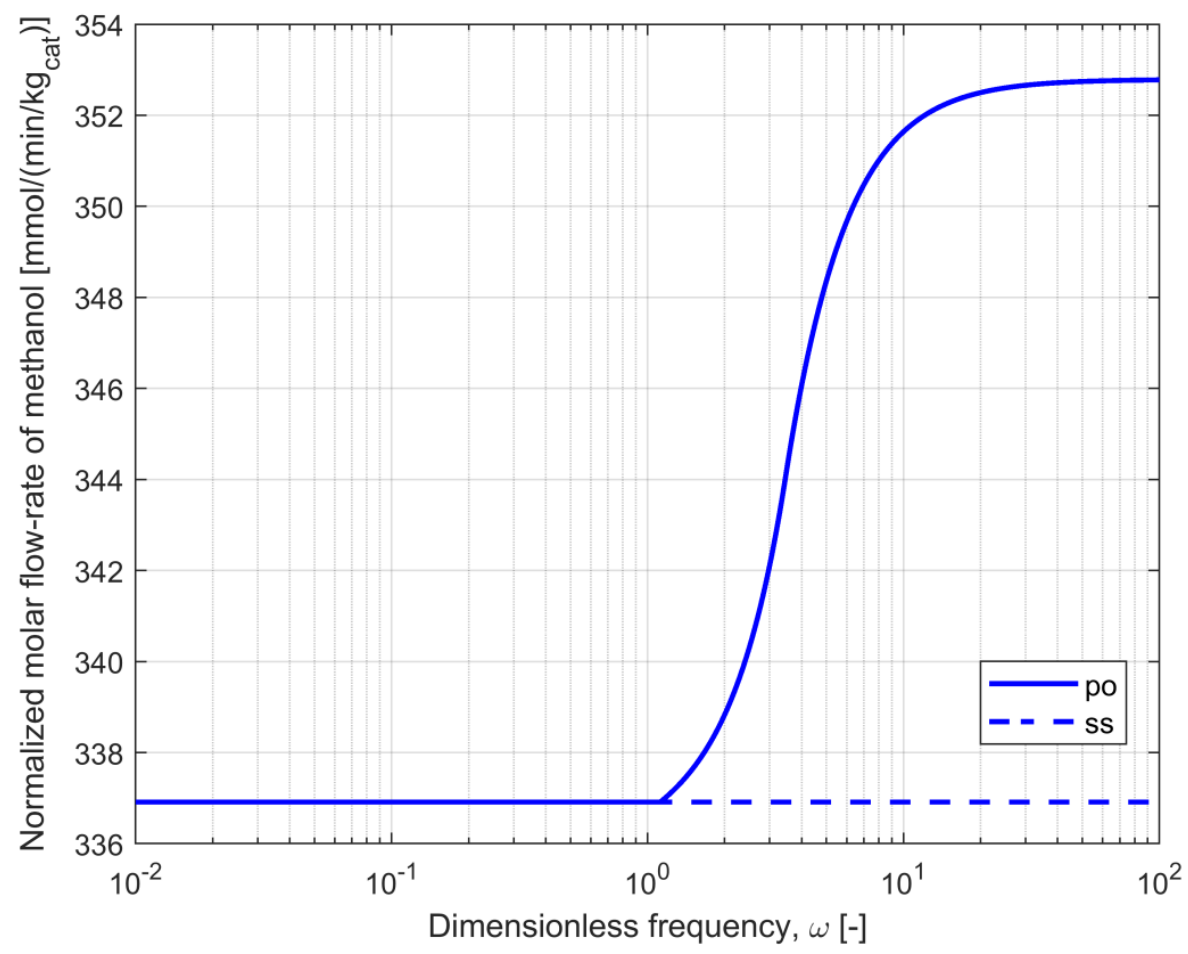

Figure E4.2 The normalized outlet molar flow-rate of methanol for steady-state and for simultaneous modulation of inlet partial pressure of $\mathrm{CO}_{2}$ and inlet volumetric flow-rate around the optimal steady-state modulated using optimal forcing parameters (forcing amplitudes and phase difference, Figure E4.1) vs. dimensionless forcing frequency. 
Appendix E5 Simultaneous modulation of partial pressures of $\mathrm{H}_{2}$ in the feed stream and inlet volumetric flow-rate

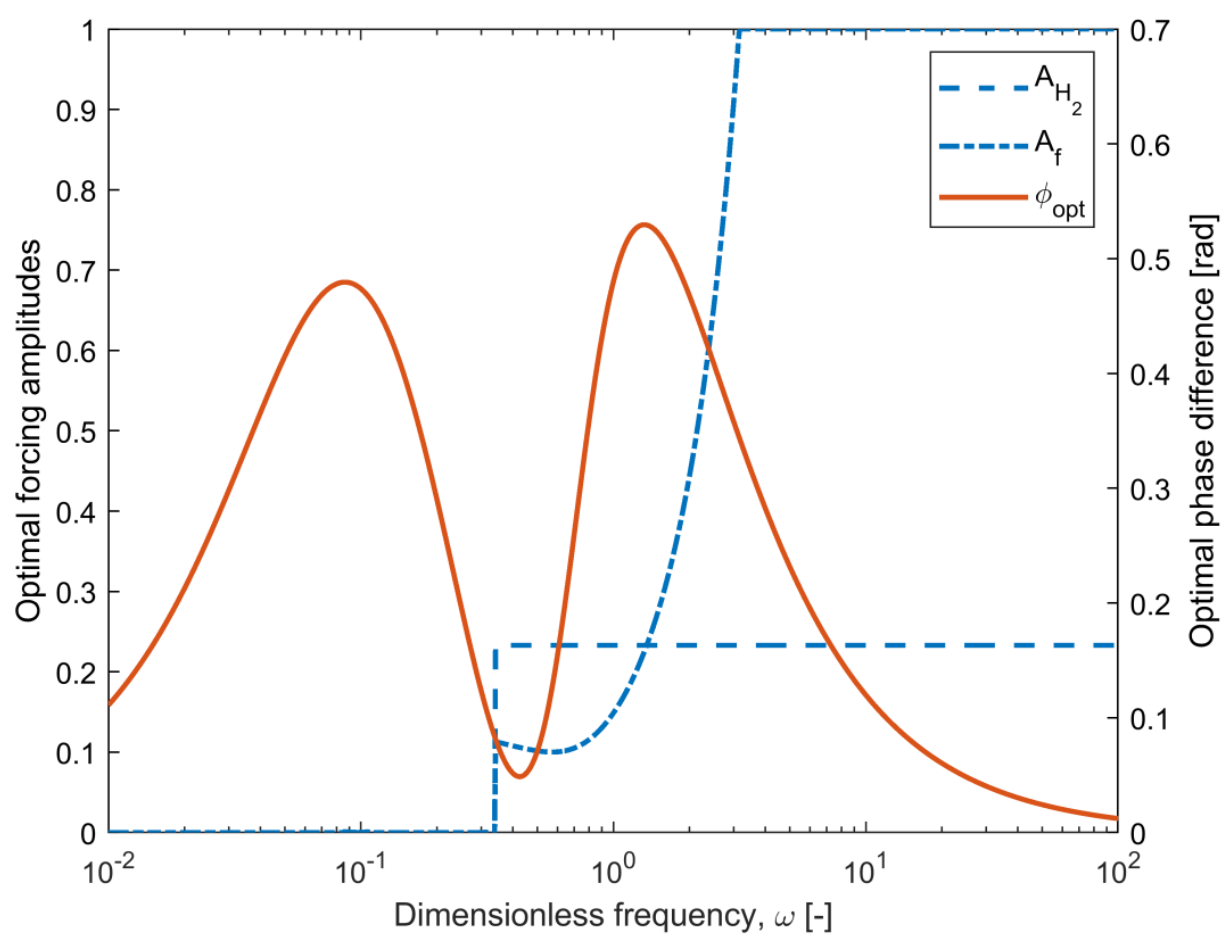

Figure E5.1 The optimal forcing parameters (forcing amplitudes and phase difference between the modulated inputs (partial pressure of $\mathrm{H}_{2}$ and inlet volumetric flow-rate)) which maximize the normalized outlet molar flow-rate of methanol, vs. dimensionless forcing frequency

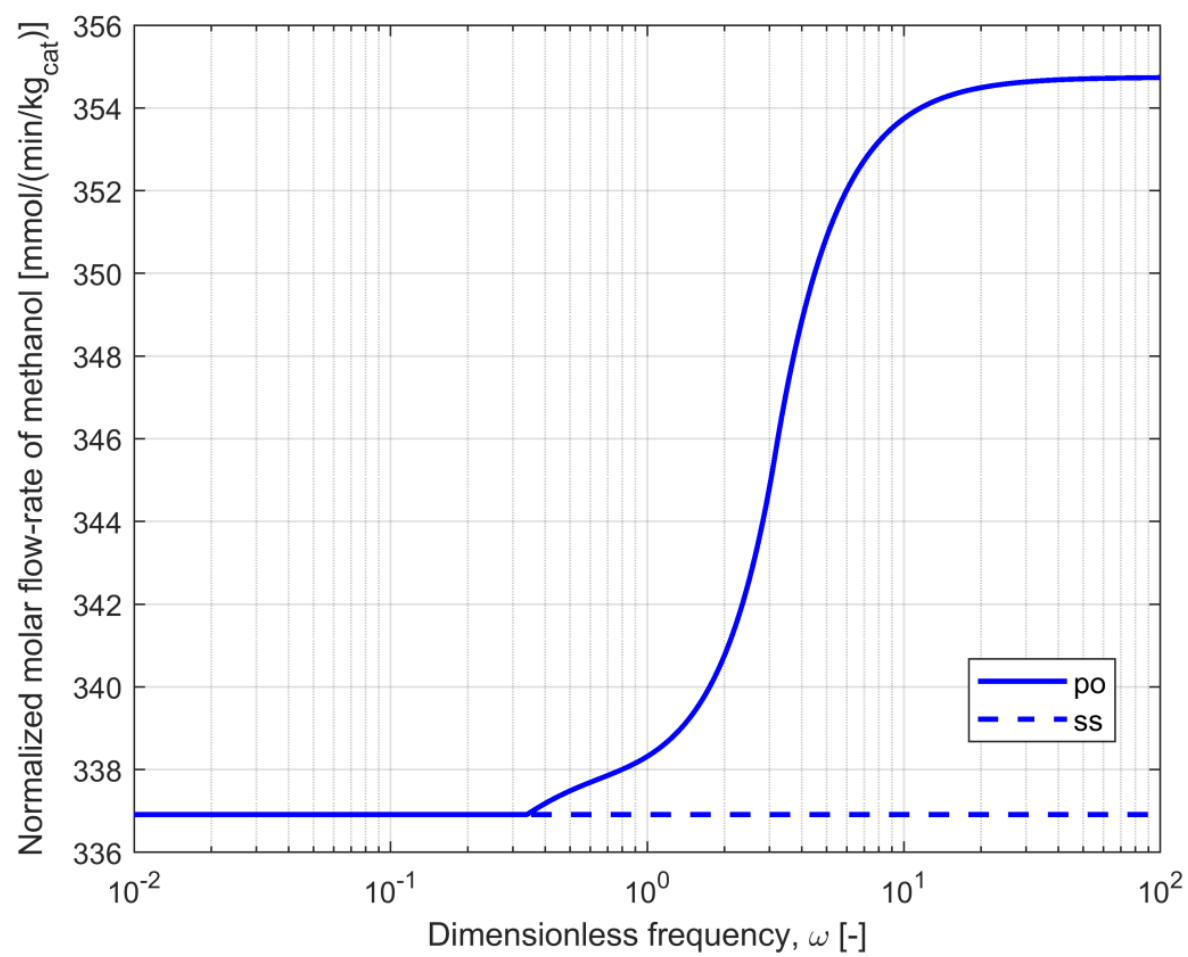

Figure E5.2 The normalized outlet molar flow-rate of methanol for steady-state and for simultaneous modulation of inlet partial pressure of $\mathrm{H}_{2}$ and inlet volumetric flow-rate around the optimal steady-state modulated using optimal forcing parameters (forcing amplitudes and phase difference, Figure E5.1) vs. dimensionless forcing frequency. 


\section{Appendix F Multi-objective optimization}

The inlet molar flow-rates of the reactants are defined as

$y_{R, 0}=\frac{p_{R, 0}}{p}$

where $\mathrm{R}$ represents the reactant $\left(\mathrm{CO}_{2}, \mathrm{CO}\right.$ or $\left.\mathrm{H}_{2}\right)$

Table F.1 Optimization variables with upper and lower boundary values (for operating in steady state regimeNo.1-3. and for periodic operation No. 1.-7.)

\begin{tabular}{|l|l|l|}
\hline No. & Optimization variable & Boundary values \\
\hline 1. & Inlet molar fraction of $\mathrm{CO}_{2}$ & $0-1$ \\
\hline 2. & Inlet molar fraction of $\mathrm{CO}$ & $0-1$ \\
\hline 3. & Inlet molar fraction of $\mathrm{H}_{2}$ & $0.5-0.85$ \\
\hline 4. & Forcing amplitude for CO inlet partial pressure modulation & $0-1$ \\
\hline 5. & Forcing amplitude for flow-rate modulation & $0-1$ \\
\hline 6. & Forcing frequency & $0.01-100$ \\
\hline 7. & Phase difference between two modulated inputs & $(-\pi)-\pi$ \\
\hline
\end{tabular}

Defined constraints used for Multi-Objective Optimization are:

1. Constraint which assures that carbon exists in feed steam

$$
y_{C O 2,0}+y_{C O, 0} \geq 0.01
$$

2. Constraint which assures constant total pressure

$$
y_{C O 2,0}+y_{C O, 0}+y_{H 2,0}=1-0.15
$$

3. Constraints which bound the maximal possible forcing amplitudes (which assure the constant total pressure (for this case given in Appendix C)

Results of Multi-objective optimization are given in Tables F.2 and F.3.

Table F.2 Results of Multi-objective optimization for steady-state regime (values of objective functions and corresponding optimized variables)

\begin{tabular}{|c|c|c|c|c|c|}
\hline & \multicolumn{2}{|c|}{ Objective functions } & \multicolumn{3}{c|}{ Optimization variables } \\
\hline No. & $\begin{array}{c}\dot{n}_{\mathrm{CH}}^{\text {norm } O H} \\
{\left[\mathrm{mmol} / \mathrm{min} / \mathrm{kg}(\mathrm{cat})_{\mathrm{cat}}\right]}\end{array}$ & $\begin{array}{c}\text { Yield of methanol } \\
\text { based on tot } \mathrm{C} \\
{[-]}\end{array}$ & $\begin{array}{c}\text { Mole fraction of } \\
\mathrm{CO}_{2} \text { in feed stream } \\
{[-]}\end{array}$ & $\begin{array}{c}\text { Mole fraction of } \\
\text { CO in feed stream } \\
{[-]}\end{array}$ & $\begin{array}{c}\text { Mole fraction of } \\
\mathrm{H}_{2} \text { in feed stream } \\
{[-]}\end{array}$ \\
\hline 1 & 417.29 & 0.4750 & 0.0351 & 0.2931 & 0.5218 \\
\hline 2 & 416.37 & 0.4943 & 0.0333 & 0.2814 & 0.5353 \\
\hline 3 & 413.39 & 0.5137 & 0.0315 & 0.2691 & 0.5494 \\
\hline 4 & 407.87 & 0.5331 & 0.0296 & 0.2562 & 0.5642 \\
\hline 5 & 399.1 & 0.5524 & 0.0277 & 0.2421 & 0.5801 \\
\hline 7 & 385.97 & 0.5718 & 0.0257 & 0.2264 & 0.5978 \\
\hline & 366.52 & 0.5912 & 0.0236 & 0.2080 & 0.6184 \\
\hline
\end{tabular}




\begin{tabular}{|c|c|c|c|c|c|}
\hline $\begin{array}{c}8 \\
\text { (OP_OSS) }\end{array}$ & 336.91 & 0.6106 & 0.0211 & 0.1850 & 0.6439 \\
\hline 9 & 287.37 & 0.6300 & 0.0179 & 0.1525 & 0.6796 \\
\hline
\end{tabular}

Table F.3 Results of Multi-objective optimization for forced periodic operation regime i.e. for the case of simultaneous modulation of $\mathrm{CO}$ and flow-rate optimization (values of objective functions and corresponding optimized variables)

\begin{tabular}{|c|c|c|c|c|c|c|c|c|c|c|}
\hline \multirow{4}{*}{ No. } & \multicolumn{2}{|c|}{ Objective functions } & \multicolumn{8}{|c|}{ Optimization variables } \\
\hline & \multirow{3}{*}{$\begin{array}{c}\dot{n}_{\mathrm{CH}_{3} \mathrm{OH}}^{\text {norm }} \\
{[\mathrm{mmol} / \mathrm{min} / \mathrm{kg}(\text { cat })]}\end{array}$} & \multirow{3}{*}{$\begin{array}{c}\text { Yield of } \\
\text { methanol } \\
\text { based on } \\
\text { tot C } \\
{[-]}\end{array}$} & \multicolumn{3}{|c|}{$\begin{array}{c}\text { Inlet variables } \\
\text { (Mole fractions in feed } \\
\text { stream of ) }\end{array}$} & \multicolumn{5}{|c|}{ Forcing parameters } \\
\hline & & & \multirow{2}{*}{$\begin{array}{c}\mathrm{CO}_{2} \\
{[-]}\end{array}$} & \multirow{2}{*}{$\begin{array}{l}\mathrm{CO} \\
{[-]}\end{array}$} & \multirow{2}{*}{$\begin{array}{l}\mathrm{H}_{2} \\
{[-]}\end{array}$} & \multicolumn{3}{|c|}{ Forcing amplitude of } & \multirow{2}{*}{$\begin{array}{c}\text { Frequency } \\
\omega[-]\end{array}$} & \multirow{2}{*}{$\begin{array}{c}\text { Phase } \\
\text { difference }\end{array}$} \\
\hline & & & & & & $\begin{array}{r}\text { flow- } \\
\text { rate } \\
{[-]}\end{array}$ & $\begin{array}{l}\mathrm{CO} \\
{[-]}\end{array}$ & $\begin{array}{l}\mathrm{N}_{2} \\
{[-]}\end{array}$ & & \\
\hline 1 & 487.16 & 0.5157 & 0.0359 & 0.2419 & 0.5722 & 1 & 0.6201 & -1 & 100 & 0.0067 \\
\hline 2 & 487.16 & 0.5157 & 0.0359 & 0.2419 & 0.5722 & 1 & 0.6201 & -1 & 100 & 0.0067 \\
\hline 3 & 487.16 & 0.5157 & 0.0359 & 0.2419 & 0.5722 & 1 & 0.6201 & -1 & 100 & 0.0067 \\
\hline 4 & 487.14 & 0.5182 & 0.0357 & 0.2405 & 0.5739 & 1 & 0.6238 & -1 & 100 & 0.0068 \\
\hline 5 & 486.79 & 0.5268 & 0.0347 & 0.2354 & 0.5799 & 1 & 0.6372 & -1 & 100 & 0.0072 \\
\hline 6 & 485.95 & 0.5355 & 0.0338 & 0.2302 & 0.5860 & 1 & 0.6516 & -1 & 99.97 & 0.0076 \\
\hline 7 & 484.57 & 0.5441 & 0.0328 & 0.2248 & 0.5923 & 1 & 0.6672 & -1 & 99.99 & 0.0080 \\
\hline 8 & 482.59 & 0.5527 & 0.0319 & 0.2192 & 0.5989 & 1 & 0.6842 & -1 & 100 & 0.0086 \\
\hline 9 & 479.91 & 0.5614 & 0.0309 & 0.2134 & 0.6057 & 1 & 0.7030 & -1 & 100 & 0.0091 \\
\hline 10 & 476.44 & 0.5670 & 0.0300 & 0.2072 & 0.6128 & 1 & 0.7238 & -1 & 100 & 0.0098 \\
\hline 11 & 472.06 & 0.5786 & 0.0290 & 0.2007 & 0.6203 & 1 & 0.7473 & -1 & 99.99 & 0.0105 \\
\hline 12 & 466.62 & 0.5873 & 0.0280 & 0.1938 & 0.6282 & 1 & 0.7741 & -1 & 99.97 & 0.0115 \\
\hline 13 & 459.9 & 0.5959 & 0.0270 & 0.1863 & 0.6367 & 1 & 0.8052 & -1 & 99.88 & 0.0125 \\
\hline 14 & 451.64 & 0.6045 & 0.0260 & 0.1781 & 0.6459 & 1 & 0.8421 & -1 & 99.97 & 0.0138 \\
\hline 15 & 441.5 & 0.6132 & 0.0248 & 0.1691 & 0.6561 & 1 & 0.8870 & -1 & 99.98 & 0.0153 \\
\hline $\begin{array}{c}16 \\
(\text { OP1) }\end{array}$ & 428.96 & 0.6218 & 0.0237 & 0.1590 & 0.6673 & 1 & 0.9432 & -1 & 99.98 & 0.0173 \\
\hline $\begin{array}{c}17 \\
(\mathbf{O P 2})\end{array}$ & 411.22 & 0.6304 & 0.0218 & 0.1479 & 0.6803 & 1 & 1 & $\begin{array}{c}- \\
0.9860\end{array}$ & 99.97 & 0.0294 \\
\hline $\begin{array}{c}18 \\
(\text { OP3 })\end{array}$ & 376.82 & 0.6391 & 0.0201 & 0.1335 & 0.6964 & 1 & 1 & 0.8897 & 99.96 & 0.0369 \\
\hline 19 & 328.4 & 0.6477 & 0.0186 & 0.1303 & 0.7011 & 1 & 1 & $\begin{array}{c}- \\
0.8684\end{array}$ & 5.01 & 0.9000 \\
\hline
\end{tabular}




\section{References}

Bailey, J.E. (1973). Periodic operation of chemical reactors: A review. Chemical Engineering Communications, 1, pp. 111-124.

Chen, C.C., Hwang, C. and Yang R.Y. (1994). Optimal periodic forcing of nonlinear chemical processes for performance improvements. The Canadian Journal of Chemical Engineering, 71, pp. 672-682.

Currie, R., Nikolić, D., Petkovska, M., Simakov, D., (2018), CO2 Conversion Enhancement in a Periodically Operated Sabatier Reactor: Nonlinear Frequency Response Analysis and Simulation-based Study, Israel Journal of Chemistry, 58(6), pp. 762-775

Douglas, J.M. (1972). Process Dynamics and Control. New Jersey: Prentice-Hall, Englewood Cliffs.

Felischak, M., Kaps, L., Hamel, C., Nikolic, D., Petkovska, M., Seidel-Morgenstern, A. (2021). Analysis and experimental demonstration of forced periodic operation of an adiabatic stirred tank reactor: Simultaneous modulation of inlet concentration and total flow-rate, Chemical Engineering Journal, 410, 128197, https://doi.org/10.1016/j.cej.2020.128197.

Felischak, M. (2020), Enhanced reactor performance by dynamic operation: Application of inherent and forced periodic behaviour, $\mathrm{PhD}$ Thesis, Faculty of Process and Systems Engineering, Otto-von-Guericke University.

Graaf, G.H., Stamhuis, E.J., Beenackers, A.A.C.M., (1988). Kinetics of low-pressure methanol synthesis, Chemical Engineering Science, 43, 12, p. 3185-3195.

Marković, A., Seidel-Morgenstern, A. and Petkovska, M. (2008). Evaluation of the potential of periodically operated reactors based on the second order frequency response functions. Chemical Engineering Research and Design, 86, pp. 682-691.

Nikolić-Paunić, D. and Petkovska, M. (2013). Evaluation of periodic processes with two modulated inputs based on nonlinear frequency response analysis. Case study: CSTR with modulation of the inlet concentration and flow-rate. Chemical Engineering Science, 104, pp. 208-219.

Nikolić, D., Seidel-Morgenstern, A. and Petkovska, M. (2014a). Nonlinear frequency response analysis of forced periodic operations of non-isothermal CSTR with single input modulations. Part I: Modulation of inlet concentration or flow-rate. Chemical Engineering Science, 117, pp. 71-84. 
Nikolić, D, Seidel-Morgenstern, A. and Petkovska, M. (2014b). Nonlinear frequency response analysis of forced periodic operations of non-isothermal CSTR with single input modulations. Part II: Modulation of inlet temperature or temperature of the heating/cooling fluid. Chemical Engineering Science, 117, pp. 31-44.

Nikolić, D., Seidel-Morgenstern, A. and Petkovska, M. (2015). Nonlinear frequency response analysis of forced periodic operation of non-isothermal CSTR with simultaneous modulation of inlet concentration and inlet temperature. Chemical Engineering Science, 137, pp. 40-58.

Nikolić, D., (2016) Forced Periodically Operated Chemical Reactors- Evaluation and Analysis by the Nonlinear Frequency Response Method, PhD Thesis, Faculty of Technology and Metallurgy, University of Belgrade.

Nikolić, D., Seidel-Morgenstern, A., Petkovska, M. (2016a). Periodic operation with modulation of inlet concentration and flow-rate Part I Non-isothermal continuous stirred-tank reactor, Chemical Engineering and Technology, Volume 39, Issue 11, p. 2020-2028

Nikolić, D., Felischak, M., Seidel-Morgenstern, A., Petkovska, M. (2016b), Periodic operation with modulation of inlet concentration and flow-rate Part II Adiabatic continuous stirred-tank reactor, Chemical Engineering and Technology, Volume 39, Issue 11, p. 2126-2134

Nikolić, D., Petkovska, M. (2016), Evaluation of Performance of Periodically Operated Reactors for Single Input Modulations of General Waveforms, Chemie Ingenieur Technik, Volume 88, Issue 11, p. 1715-1722

Nikolić, D., Seidel-Morgenstern, A., Petkovska, M., (2020), Nonlinear frequency response analysis of forced periodic operations with simultaneous modulation of two general waveform inputs with application on adiabatic CSTR with square-wave modulations, Chemical Engineering Science, 226

Petkovska, M., Nikolić, D., Marković, A. and Seidel-Morgenstern, A. (2010). Fast evaluation of periodic operation of a heterogeneous reactor based on nonlinear frequency response analysis. Chemical Engineering Science, 65, pp. 3632-3637.

Petkovska, M. and Seidel-Morgenstern, A. (2013). Evaluation of periodic processes. In: Silveston, R.R. and Hudgins, R.R., ed., Periodic Operation of Reactors, Amsterdam: Elsevier, pp. 387-413.

Petkovska, M., Nikolić, D., Seidel-Morgenstern, A., (2018), Nonlinear Frequency Response Method for Evaluating Forced Periodic Operations of Chemical Reactors, Israel Journal of Chemistry 58(6), pp. 1-20. 
Renken, A. (1972). The use of periodic operation to improve the performance of continuous stirred tank reactors. Chemical Engineering Science, 27, pp. 1925-1932.

Schadlich, K., Hoffmann, U. and Hofmann, H. (1983). Periodical operation of chemical processes and evaluation of conversion improvements. Chemical Engineering Science, 38, pp. $1375-1384$.

Seidel., C., Jorke, A., Vollbrecht, B., Seidel-Morgenstern, A., Kienle, A., (2018). Kinetic modeling of methanol synthesis from renewable resources, Chemical Engineering Science, 175, $130-138$

Seidel., C., Jorke, A., Vollbrecht, B., Seidel-Morgenstern, A., Kienle, A., (2020), Corrigendum to (Kinetic modeling of methanol synthesis from renewable resources, Chemical Engineering Science, 175 (2018), 130-138), Chemical Engineering Science 223, 115724.

Seidel, C, Nikolić, D., Felischak, M., Petkovska, M., Seidel-Morgenstern, A., Kienle, A., Optimization of Methanol Synthesis under Forced Periodic Operation. In preparation.

Silveston, P.L. (1987). Periodic operation of chemical reactors-a review of the experimental literature. Sadhana, 10, pp. 217-246.

Silveston, P., Hudgins, R. and Renken, A. (1995). Periodic operation of catalytic reactors introduction and overview, Catalysis Today, 25 pp. 91-112.

Silveston, P.L. (1998). Composition Modulation of Catalytic Reactors. Amsterdam: Gordon and Breach Science Publishers.

Silveston, P.L. and Hudgins, R.R. (editors) (2013). Periodic Operation of Reactors, Amsterdam: Elsevier

Sterman L.E. and Ydstie B.E. (1990a). Unsteady-state multivariable analysis of periodically perturbed systems. Chemical Engineering Science, 45, pp.737-749.

Sterman, L. E. and Ydstie B. E. (1990b). The steady-state process with periodic perturbations. Chemical Engineering Science 45, pp.721-736.

Sterman L. E. and Ydstie B.E (1991). Periodic forcing of the CSTR: an Application of the Generalized П-Criterion, AIChE Journal 37, pp. 986-996.

Van Gerven, T. and Stankiewicz A., (2009). Structure, Energy, Synergy, Time - The Fundamentals of Process Intensification, Ind Eng Chem Res, 48, 5, pp.2465-2474.

Vollbrecht B., 2007. Zur Kinetic der Methanolsynthese an einem technischen Cu/ZnO/Al2O3Katalysator. $\mathrm{PhD}$ thesis, Otto-von-Guericke-Universitat Magdeburg. 
Volterra, V. (1959). Theory of Functionals and Integral and Integrodifferential Equations. New York: Dover.

Weiner, D.D. and Spina, J.F. (1980). Sinusoidal Analysis and Modeling of Weakly Nonlinear Circuits. New York: Van Nostrand Reinhold Company

Živković L., Vidaković-Koch T., Petkovska M., (2020a). Computer-Aided Nonlinear Frequency Response Method for Investigating the Dynamics of Chemical Engineering Systems, Processes, 8, 1354, doi;10.3390/pr8111354

Živković L., Milić V., Vidaković-Koch T., Petkovska M., (2020b). Rapid Multi-Objective Optimization of Periodically Operated Processes Based on the Computer-Aided Nonlinear Frequency Response Method, Processes, 8, 1357, doi;10.3390/pr8111357. 